\title{
Linajes urbanos y Parientes Mayores en Guipúzcoa a finales de la Edad Media $(1450-1520)^{1}$
}

\author{
Urban lineages and "Parientes Mayores" in Guipuzcoa at the end of the \\ Middle Ages (1450-1520)
}

\author{
Álvaro Aragón RuANo \\ Universidad del País Vasco \\ alvaro.aragon@ehu.es
}

\begin{abstract}
RESUMEN
Durante el tránsito de la Edad Media a la Edad Moderna los linajes urbanos y los Parientes Mayores siguieron compartiendo intereses comunes y estrechos lazos sanguíneos y económicos, que les permitieron monopolizar el poder de las villas guipuzcoanas y copar la mayor parte de los cargos concejiles, dando lugar a un proceso de oligarquización. El trabajo de investigación se vale de métodos prosopográficos para analizar una serie de fuentes inéditas o escasamente utilizadas hasta la fecha, complementadas por otras suficientemente conocidas, para demostrar que, a pesar de lo que ha venido manteniendo la historiografía, los Parientes Mayores no fueron vencidos y desplazados por los linajes urbanos, si no que se produjo una simbiosis entre ambos, lo que les permitió seguir controlando la vida política local y provincial de forma directa o indirecta.
\end{abstract}

Palabras clave: Guipúzcoa. Parientes mayores. Villas. Linajes urbanos. Monopolización. Oligarquización. ss. XV-XVI.

\begin{abstract}
During the transition from the Middle Ages to the Early Modern Period, urban lineages and the "Parientes Mayores" continued sharing common interests and close family and economic ties, which enabled them to monopolize the government in guipuzcoan towns and to obtain the majority of the council positions, giving way to a process of oligarchization. The research employs prosopographic methods to analyse unpublished or poorly used sources, complemented by others sufficiently known, in order to demonstrate that, in spite of what the historiography has claimed to date, the "Parientes Mayores" were not defeated and displaced by urban lineages. On the contrary, a symbiosis occurred, which allow the "Parientes Mayores" to continue controlling local and regional politics directly or indirectly.
\end{abstract}

Key words: Guipuzcoa. "Parientes mayores". Towns. Urban lineages. Monopoly. Oligarchy. 15th-16th centuries.

Sumario: 1. Introducción. 2. La oligarquización y el monopolio de los cargos. 3. Linajes urbanos y Parientes Mayores. 4. Conclusiones.

${ }^{1}$ Este artículo se ha elaborado en el marco del proyecto de investigación financiado por el Ministerio de Ciencia e Innovación, titulado "Poder, sociedad y fiscalidad en el entorno geográfico de la Cornisa Cantábrica en el tránsito del Medievo a la Modernidad", HAR2011-27016-C02-01, que forma parte del Proyecto Coordinado HAR2011-27016-C02-00 y participa en la Red “Arca Comunis". 


\section{INTRODUCCIÓN}

Mucho se ha hablado y se sigue debatiendo en torno el triunfo de las villas sobre los Parientes Mayores ${ }^{2}$, pero ¿qué hay de cierto en todo ello?. A pesar de todo lo especulado, hasta el momento no existe trabajo alguno que, partiendo del análisis prosopográfico, haya llevado a cabo un estudio pormenorizado de la nómina de personajes que entre mediados del siglo XV y comienzos del siglo XVI ocuparon los principales cargos concejiles ${ }^{3}$. Una labor de ese tipo permitiría calibrar si los linajes urbanos estaban completamente desvinculados de los Parientes Mayores, a los que supuestamente desbancaron, o si, por el contrario, existían fuertes vínculos sanguíneos, familiares y fraternales entre ambos grupos ${ }^{4}$. Precisamente esa es la principal finalidad de la presente investigación. Es cierto que la escasez y parquedad de las fuentes limitan a priori bastante la labor investigadora, pero afortunadamente la aparición de nueva documentación y la aplicación de nuevas metodologías y enfoques, además de la combinación de diferentes tipologías documentales, están permitiendo dar considerables pasos en este sentido. Hace ya casi dos décadas que protagonizamos un intento en ese sentido, aunque lo limitado de la documentación y del marco cronológico objeto de estudio (1511-1550), no nos permitió si no lanzar algunas hipótesis ${ }^{5}$. La presente investigación permitirá ir más allá, comprobar, corroborar y ampliar algunas de las conclusiones a las que por aquel entonces se llegaba.

Como adelantábamos, las fuentes no son muy numerosas, pero un estudio concienzudo y complementario de las diversas tipologías nos ha permitido establecer unas bases sólidas. Por un lado, contamos con las cuentas municipales de Mondragón, entre 1501 y 1520 , y con las de Motrico, entre 1502 y 1508, y por otro, con los repartimientos de Zumaya entre 1502 y 1517, los repartimientos de Villafranca

2 Álvarez llano, R.g.: Historia económica del País Vasco-Navarro. Desde los orígenes hasta comienzos del siglo XXI, Biblioteca Arellano Isusquiza, Bilbao, 2008, 75-102; BAZÁN, I. (DIR.): De Túbal a Aitor. Historia de Vasconia, Bilbao, 2002, 291; DÍAZ DE DURANA, J.R.: "Linajes y bandos en el País Vasco durante los siglos XIV y XV", La familia en la edad media: XI Semana de Estudios Medievales, Nájera, del 31 de julio al 4 de agosto de 2000, 2001, Nájera, 253-284 y "Las luchas de bandos: ligas nobiliarias y enfrentamientos banderizos en el nordeste de la Corona de Castilla", Conflictos sociales, politicos e intelectuales en la España de los siglos XIV y XV: XIV Semana de Estudios Medievales, Nájera, del 4 al 8 de agosto de 2003, Nájera, 2004, 81-112; y LEMA, J.A., FERNÁNDEZ DE LARREA, J.A., GARCÍA FERNÁNDEZ, E, MUNITA, J.A., DÍAZ DE DURANA, J.R.: El triunfo de las élites urbanas guipuzcoanas: nuevos textos para el estudio del gobierno de las villas y de la Provincia (1412-1539), Diputación Foral de Guipúzcoa, Donostia, 2002, 30 .

3 En el año 1998, Borja Aguinagalde ya era consciente del mismo vacío historiográfico. AGUINAGALDE, B.: "La genealogía de los Solares y Linajes guipuzcoanos bajomedievales. Reflexiones y ejemplos", La lucha de bandos en el País Vasco: de los Parientes Mayores a la Hidalguía Universal. Guipúzcoa, de los bandos a la Provincia (siglos XIV a XVI), Bilbao, UPV, 1998, 155.

4 El mismo autor califica de "tópico historiográfico" el enfrentamiento de los Parientes Mayores con los linajes urbanos: “...uno de los más interesantes tópicos historiográficos de todos los tiempos: frente a los Parientes Mayores, una serie de linajes urbanos forman las oligarquías que les combatirán y vencerán su modelo, suplantándolo por el suyo propio”. Ibidem, p. 157.

5 ALBerdi lonbide, X., ARAGÓN RUANO, A.: "La pervivencia de los Parientes Mayores en el poder político local de Gipuzkoa durante el período 1511-1550", Las Juntas en la conformación de Gipuzkoa hasta 1550, Diputación Foral de Gipuzkoa, San Sebastián, 1995, 287-312. 
de Ordicia entre 1451 y 1518 -parte de los cuales se pueden encontrar en el Libro de repartimientos (1511-1611)-, ambos incluidos en diversos procesos judiciales procedentes de la Real Chancillería de Valladolid, y los repartimientos de Azpeitia entre 1515 y 1520 -insertos en las Cuentas de Propios y Arbitrios (1515-1538)- ${ }^{6}$. De todas formas, para el caso de Villafranca de Ordicia y de Mondragón existe, afortunadamente, una fuente complementaria de inestimable valor: nos estamos refiriendo a los padrones fiscales que permiten conocer el nombre y apellidos de la mayor parte de los vecinos y aproximarse al estudio de sus rentas y patrimonios, aunque, como ha puesto de relieve García Fernández, puede que exista algún porcentaje de error, fraude o manipulación ${ }^{7}$. En el caso de Ordicia son siete los padrones que se conservan $(1506,1521,1522,1525,1526,1543$ y 1549$)$ y que se han utilizado tratando de analizar la evolución, los cambios y continuidades existentes en la nómina de principales de la villa de Ordicia ${ }^{8}$. En cuanto a Mondragón, el empadronamiento de 1535 ya fue analizado extensamente por Achón Insausti ${ }^{9}$. Además se han conservado para la época algunas ordenanzas municipales (Cestona, Deva, Oyarzun, Rentería y San Sebastián), en un arco cronológico que nos lleva desde el siglo XIV hasta el siglo XVI. Por último, apenas nos han llegado series de actas capitulares y las únicas que existen, las de Fuenterrabía ${ }^{10}$, son de fechas tardías y aparecen incompletas. A toda esta documentación se le ha aplicado un análisis cruzado tratando de localizar a los principales oficiales concejiles, su pertenencia linajuda, las redes familiares y su carrera económica, política y administrativa, desde las instancias locales hasta las reales, pasando por las regionales. La prosopografía ha sido en este caso un excelente instrumento para conocer a los protagonistas ${ }^{11}$.

\section{LA OLIGARQUIZACIÓN Y EL MONOPOLIO DE LOS CARGOS}

En líneas generales, los oficios concejiles asistieron a un fenómeno de oligarquización y monopolización, en un período embrionario de gestación de importantes cambios, que marcarían todo la edad moderna, a consecuencia del fortalecimiento

\footnotetext{
${ }^{6}$ LEMA PUeyo, J.A., GÓmEZ LAgo, J.M.: Archivo Municipal de Mondragón. Tomo IV. Libro de cuentas del concejo. 1501-1520. Copias de las Juntas Generales de Gipuzkoa. 1510-1520, Eusko Ikaskuntza, San Sebastián, 1998, 1-240; Herrero, v.: Fuentes medievales del Archivo Municipal de Mutriku (12371520), Eusko Ikaskuntza, San Sebastián, 2007, 101-209; Archivo de la Real Chancillería de Valladolid (ARCHV), Pleitos civiles, Escribanía Zarandona y Balboa, Pleitos Fenecidos, 922/1, 1294/3, 1295/1 y 1401/1; Archivo Municipal de Ordicia (AMOr), Libro de Repartimientos (1511-1611), fols. 1 r ${ }^{\mathrm{o}}-8$ r ro y Archivo Municipal de Azpeitia (AMAzp), 774-01.

7 GARCÍA FERNÁNDEZ, E.: "La población de la villa guipuzcoana de Guetaria a fines de la Edad Media", En la España Medieval, 22 (1999), 327.

8 ARCHV, Pleitos civiles, Escribanía Zarandona y Balboa, Pleitos Fenecidos, 1294/3 y 1295/1.

9 ACHÓn JUARISTI, J.A.: “A voz de concejo”. Linaje y corporación urbana en la constitución de la Provincia de Gipuzkoa, Diputación Foral de Gipuzkoa, 1995, 258-301.

${ }_{10}$ Archivo Municipal de Hondarribia, A, 1, 1.

${ }^{11}$ GARCía PEDRAZA, A.: "La prosopografía de los intermediarios fiscales del Reino de Granada (1492-

1515). Una historia por hacer”, Crónica Nova, 31 (2005), 147-195.
} 
de las estructuras de los estados modernos ${ }^{12}$. El resultado de ese proceso fue que la nómina de familias y personajes que desempeñaron dichos cargos fue muy reducida, con tendencia además a la endogamia, porque la mayoría de ellas acabarán de una forma u otra vinculándose. Prácticamente desde la fundación de las villas, al menos desde que existen evidencias documentales, la relación de familias al frente de las instituciones concejiles se repite, desde el siglo XIV hasta el siglo XVIII.

Tabla 1: Salarios de los oficiales concejiles (1489-1535) (maravedís)

\begin{tabular}{|c|c|c|c|c|c|c|}
\hline \multirow[b]{2}{*}{ Cargo } & \multirow[b]{2}{*}{ Motrico } & \multirow[b]{2}{*}{ Ordicia } & \multirow[b]{2}{*}{ Oyarzun } & \multirow{2}{*}{$\begin{array}{c}\text { San } \\
\text { Sebastián }\end{array}$} & \multicolumn{2}{|c|}{ Zumaya } \\
\hline & & & & & $\begin{array}{c}\text { Antes de } \\
1515\end{array}$ & $\begin{array}{c}\text { Después de } \\
1515\end{array}$ \\
\hline Alcalde & 1.000 & 600 & 750 & 2.000 & 400 & 500 \\
\hline $\begin{array}{l}\text { Síndico } \\
\text { procurador }\end{array}$ & & & & 1.500 & 400 & 500 \\
\hline Escribano fiel & 1.000 & 500 & 1.500 & 3.000 & 400 & 500 \\
\hline $\begin{array}{l}\text { Jurado } \\
\text { Mayor }\end{array}$ & & 400 & 750 & 3.000 & 200 & 500 \\
\hline $\begin{array}{l}\text { Jurado } \\
\text { Menor }\end{array}$ & & & 375 & 1.500 & 100 & 200 \\
\hline Jurado Sayaz & & & & & 100 & 200 \\
\hline Velador & & & & & 500 & 625 \\
\hline $\begin{array}{l}\text { Regidor- } \\
\text { Diputado }\end{array}$ & 500 & & 750 & 1.500 & & \\
\hline Fiel Bolsero & 1.000 & 400 & 750 & 3.000 & & \\
\hline Abogado & 3.000 & $1.500-1.750$ & & & & \\
\hline
\end{tabular}

Fuente: AMO, C, 4, 8, 1; ARCHV, Pleitos Civiles, Escribanía Zarandona y Balboa, Pleitos Fenecidos, 922/1; ARCHV, Pleitos civiles, Zarandona y Balboa, Pleitos Fenecidos, 1295/1; AYERBE IRIBAR, M.R.: "Las ordenanzas, etc., 37 y HERRERO, V.: Fuentes medievales, etc., 101-209.

Los salarios cobrados por el desempeño de cargos concejiles fueron un importante atractivo para estos grupos, pero sin duda la razón última estaba en la capacidad de acción y poder que conllevaban. Por ello el acceso a los cargos se fue cerrando y dificultando. A medida que nos vamos alejando del siglo XV y va avanzando el siglo XVI el nivel de exigencia para ocupar un cargo concejil es mayor. Tres eran las condiciones básicas: la riqueza, la radicación o vecindad y la capacidad de obrar $^{13}$. La necesidad de estar en posesión de una cierta riqueza era la principal

${ }^{12}$ En palabras de Piquero Zarauz y de Díaz de Durana, el $50 \%$ de la riqueza estaba en poder del 10 $\%$ de la fracción superior de la población, la mitad inferior de los contribuyentes solo controlaba el $10 \%$ de dicha riqueza, como atestiguan los casos de Villarreal de Urrechu y Mondragón. PIQUERo ZARAUZ, s., DÍAZ DE DURANA, J.R.: "De la fiscalidad municipal a la sociedad: notas sobre las desigualdades económicas y contributivas en Guipúzcoa (siglo XV-XVI)", La lucha de bandos en el País Vasco..., 524.

13 Corral garcía, e.: El Mayordomo de Concejo en la Corona de Castilla (s. XIII-XVIII), El consultor de los ayuntamientos y de los juzgados, Madrid, 1991, 69-79; SORIA SESÉ, L.: Derecho municipal guipuzcoano. Categorías normativas y comportamientos sociales, IVAP, Oñate, 1992, 
exigencia de acceso al poder municipal; las obligaciones fiscales de los vecinos también condicionaban sus derechos políticos. Generalmente, los oficios superiores, los del regimiento, quedaban reservados para los pecheros enteros, mientras que los inferiores se adjudicaban a aquellos que cotizaban en menor cuantía. La justificación de este hecho está en la necesidad de que quienes administraban los bienes e ingresos municipales dispusiesen de un patrimonio suficiente con que responsabilizarse de los perjuicios derivados de su gestión. La recopilación de ordenanzas de 1533 de Azpeitia exigía ser pagador mayor o entero para desempeñar los cargos de alcalde, fiel y regidor, mientras que para ser jurado ejecutor bastaba con ser medio, cuarto o sexto pechero. En el caso de las ordenanzas de Oyarzun sobre la elección de oficiales del concejo, redactada en 1535, se solicitaba un mínimo de $50.000 \mathrm{mrs}$ de hacienda en bienes en la tierra de Oyarzun, cifra similar a los 45.000 mrs que coetáneamente se exigían como mínimo para estar encabezado en la suerte entera en Mondragón o los 60.000 mrs de Tolosa en 1532 ${ }^{14}$; el establecimiento de millares y niveles de renta, aunque comenzó a desarrollarse en la segunda década, no se afianzó hasta los años treinta del siglo XVI. De esta forma, el acceso al poder político pleno, como electores y elegibles, quedó limitado a un reducido número de vecinos hidalgos, proceso cada vez más evidente desde el establecimiento del regimiento. En el caso de Mondragón, después de la abolición de los bandos de 1490, y hasta 1513, encontramos un sistema de elección cooptativo: son los cargos nucleares salientes los que eligen a los cuatro electores que nombran los nuevos oficiales, también en el caso de los diputados, cargo de nuevo cuño, que es elegido por el alcalde, regidores y procurador. En 1513 el común de Mondragón protestó, exigiendo su participación en la elección. Para acallar las quejas se propuso un sistema insaculatorio, en el que comenzaba a vislumbrarse la exigencia de millares, y se prohibió que los oficiales de los dos últimos años fuesen electores. En realidad, este "cerramiento" del concejo fue un método de reclutamiento que favoreció la reproducción en el poder de la oligarquía y la perpetuación de clientelas, basadas en una reciprocidad desigual y asimétrica de favores y obligaciones ${ }^{15}$.

La obligatoria habitación permanente en el territorio sobre el que la villa ejercía jurisdicción era el segundo requisito, aunque no precisaba una antigüedad de más allá de seis meses o un año. En este caso encontramos dos modelos diferentes: aquellos municipios donde las banderías monopolizaban los cargos y se repartían los oficios y aquellos otros donde el regimiento se implantó de una forma natural. En el primer caso, el progresivo desarrollo del regimiento provocó cambios en el sistema de elección de los oficiales, que desde entonces se designaron por cooptación, tratando de evitar los inconvenientes que generaban las banderías. Desde ese momento se estableció un reparto de cargos entre los vecinos de la villa y los de la tierra, cuya sociedad parental continuaba teniendo gran poder, a pesar de su teórica

387-398; TRUCHUELO GARCÍA, S.: La representación de las corporaciones locales guipuzcoanas en el entramado político provincial (siglos XVI-XVII), Diputación Foral de Gipuzkoa, San Sebastián, 1997, 80-85 y Tolosa en la Edad Moderna. Organización y gobierno de una villa guipuzcoana (siglos XVIXVII), Sociedad de Ciencias Aranzadi, Tolosa, 2006, 131-136.

14 AMO, C, 4, 8, 1; ACHÓN InSAUSti, J.A.: "A voz de concejo..., 258 y truchuElo García, s.: Tolosa en la Edad Moderna..., 131.

15 ACHÓn INSAUSTI, J.A.: “A voz de concejo..., 251-257. 
desaparición. En aquellos concejos en los que el regimiento se estableció sin graves circunstancias previas que lo exigieran, fuera cual fuese el sistema de designación, los cargos se reservaron a los habitantes intramuros, que en el caso de Mondragón constituían el indiscutido núcleo dirigente.

En cuanto a la tercera de las exigencias, la de la capacidad de obrar del sujeto, en realidad encerraba una amplia variedad de situaciones y circunstancias. En primer lugar, debía ser mayor de edad, es decir, al menos veinticinco años, para aquellos cargos con facultad jurisdiccional, y veinte para aquellos con facultad únicamente gubernativa; en Mondragón el límite superior se situaba en sesenta años. En segundo lugar, debía ser hidalgo y persona de buena vida y fama, generalmente vinculada a la condición de casado, si bien se permitía a solteros mayores de veinticinco años, aunque estuviesen bajo potestad y en casa de su padre, ocupar cargos concejiles, puesto que ya eran sujetos fiscales. Por ello, se descartaba a personas con enfermedades o taras físicas y psicológicas. Además, en la misma línea restrictiva, se prohibía compaginar actividades viles y la gestión concejil; así en 1492 en Mondragón se prohibió a carniceros, buhoneros y taberneros que ejerciesen el cargo de alcaldes, regidores o procuradores mientras desarrollasen sus oficios y tareas, a fin de que los intereses privados no interfiriesen en los públicos, sobre todo en casos como el de regidor, quien controlaba todo lo relacionado con el abastecimiento, pesos y medidas ${ }^{16}$. En tercer lugar, la alfabetización era el elemento más restrictivo, sin duda, del sistema. Según Soria Sesé, a diferencia de las restantes condiciones de acceso al poder político, la condición de la alfabetización no surgió ni se reguló hasta la tercera década del siglo XVI. Con anterioridad, esta exigencia se difuminaba bajo los vagos términos de sapiencia e idoneidad. Fue en las ordenanzas de 1529 enviadas a la provincia por el rey cuando apareció por primera vez la exigencia de leer y escribir, unida a la suficiente riqueza, la mayoría de edad, la buena fama, la experiencia y el conocimiento de la lengua castellana ${ }^{17}$. Siendo como fue una respuesta al deseo de restringir más todavía el acceso a los cargos, no es de extrañar que fuesen las grandes villas las pioneras en introducir dicha medida, tratando de evitar la llegada de advenedizos. A San Sebastián en 1530 le siguió Tolosa dos años después ${ }^{18}$, mientras que en el resto de municipios la aplicación fue más lenta, con grandes reticencias. No fue hasta 1571 cuando la Junta General de Rentería, precisamente a instancia de San Sebastián y Tolosa, extendió la obligación para todos los alcaldes de Guipúzcoa. De todas formas, la exigencia ya se aplicaba de facto con anterioridad, puesto que un número importante, si no la mayoría, de aquellos que ocuparon cargos concejiles entre 1450 y 1520 estaban alfabetizados. En último lugar, se debían mantener ciertos intervalos temporales para volver a desempeñar los cargos concejiles.

El proceso de diferenciación interna en las comunidades urbanas se había iniciado en la etapa medieval, pero fue jurídicamente sancionada en la primera mitad

16 LEMA PUEYO, J.A., GÓMEZ LAgo, J.M.: Archivo Municipal de Mondragón..., p. 255.

17 En el caso de Guetaria, fueron las ordenanzas municipales de 1549 las que exigieron al que aspirase a mayordomo saber leer y tener bienes valorados en al menos tres mareajes. GARCÍA FERNÁNDEZ, E., "La población de la villa..., 337.

18 Truchuelo garcía, s.: Tolosa en la Edad Moderna..., 42-51. 
del siglo XVI, a partir de la consolidación del concejo cerrado, de la aparición del regimiento y de la especificación de los mencionados requisitos a través de las ordenanzas municipales. El concejo general de vecinos, aunque no desapareció, se vio relegado a un segundo plano político por el regimiento. El concejo cerrado fue progresivamente asumiendo funciones decisorias y representativas de la asamblea general. Los requisitos descritos anteriormente contribuyeron a la desvirtuación del concejo abierto, reservando el acceso a los oficios concejiles y provinciales para aquellos individuos más importantes en los ámbitos socio-político y económico. Llega, por tanto, el momento de conocer más de cerca quiénes fueron esos individuos $^{19}$.

Tabla 2: oficiales concejiles en Zumaya (1502-1517)

\begin{tabular}{|c|c|c|c|c|c|c|c|}
\hline Nombre & $\frac{\frac{\pi}{\frac{\pi}{\pi}}}{\frac{\mathrm{e}}{2}}$ & 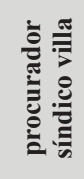 & 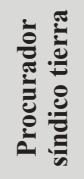 & 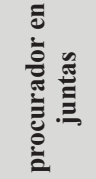 & 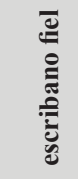 & 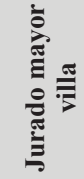 & 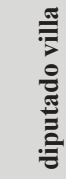 \\
\hline Arteaga, Beltrán de & $\begin{array}{l}1504 \\
1505\end{array}$ & & & & & & \\
\hline Arteaga, Juan de & & & & 1517 & & & \\
\hline $\begin{array}{l}\text { Arteaga, Juan } \\
\text { Martínez de }\end{array}$ & 1513 & & & $\begin{array}{l}1505 \\
1515\end{array}$ & & & 1517 \\
\hline $\begin{array}{l}\text { Arteaga, Juan Ruiz } \\
\text { de }\end{array}$ & & & & 1502 & & & \\
\hline $\begin{array}{l}\text { Arteaga, Martín } \\
\text { Sánchez de }\end{array}$ & 1509 & & & & & & \\
\hline $\begin{array}{l}\text { Dornuategui, } \\
\text { Fernando de }\end{array}$ & & & & 1506 & & & \\
\hline $\begin{array}{l}\text { Dornuategui, Juan } \\
\text { Fernández de }\end{array}$ & $\begin{array}{l}1511 \\
1512\end{array}$ & & & & & & \\
\hline $\begin{array}{l}\text { Dornuategui, Martín } \\
\text { Fernández de }\end{array}$ & & 1506 & & & & & 1512 \\
\hline Elcano, Antón de & & 1515 & & 1515 & & & 1516 \\
\hline $\begin{array}{l}\text { Elorriaga, Juan Pérez } \\
\text { de }\end{array}$ & $\begin{array}{l}1509 \\
1515\end{array}$ & 1516 & & $\begin{array}{l}1509 \\
1513 \\
1515 \\
1517 \\
\end{array}$ & $\begin{array}{l}1516 \\
1517\end{array}$ & 1516 & $\begin{array}{l}1513 \\
1517\end{array}$ \\
\hline $\begin{array}{l}\text { Elorriaga, Juan } \\
\text { Sebastián de }\end{array}$ & & & & & & 1509 & \\
\hline $\begin{array}{l}\text { Indaneta, Andrés } \\
\text { Pérez de }\end{array}$ & $\begin{array}{l}1515 \\
1517 \\
\end{array}$ & & & 1504 & & & $\begin{array}{l}1503 \\
1516\end{array}$ \\
\hline $\begin{array}{l}\text { Indaneta, Diego } \\
\text { Pérez de }\end{array}$ & 1517 & & & & & & 1516 \\
\hline
\end{tabular}

${ }^{19}$ Las tablas que se aportan contienen una pequeña parte de la información recopilada, por supuesto por razones de espacio; en próximas publicaciones confiamos en poder publicarlas integramente. A fin de probar la mencionada oligarquización y monopolización, se ha optado por incluir únicamente los nombres de los miembros de aquellos linajes que contaban con más de un cargo concejil. 


\begin{tabular}{|c|c|c|c|c|c|c|c|}
\hline $\begin{array}{l}\text { Indaneta, Francisco } \\
\text { de }\end{array}$ & & & & & & & 1517 \\
\hline $\begin{array}{l}\text { Indaneta, Martín } \\
\text { Pérez de }\end{array}$ & 1507 & & & & & & \\
\hline $\begin{array}{l}\text { Indaneta, Pedro } \\
\text { Fernández de }\end{array}$ & $\begin{array}{l}1504 \\
1505\end{array}$ & & & & & & \\
\hline $\begin{array}{l}\text { Iraeta, Juan Martínez } \\
\text { de }\end{array}$ & & & & & & & $\begin{array}{l}1516 \\
1517\end{array}$ \\
\hline $\begin{array}{l}\text { Iraeta, Pedro Martínez } \\
\text { de }\end{array}$ & & $\begin{array}{l}1511 \\
1512\end{array}$ & & & & & \\
\hline Irure, Juan de & & $\begin{array}{l}1502 \\
1507\end{array}$ & & 1502 & & 1507 & \\
\hline Irure, Martín López de & & $\begin{array}{l}1513 \\
1517\end{array}$ & & & & $\begin{array}{l}1513 \\
1517\end{array}$ & \\
\hline $\begin{array}{l}\text { Mirubia, Juan de } \\
\text { (ferrementero) }\end{array}$ & & & \begin{tabular}{|c|}
1503 \\
$1510-1512$
\end{tabular} & & & & 1517 \\
\hline $\begin{array}{l}\text { Mirubia, Martín Díaz } \\
\text { de }\end{array}$ & 1502 & & & 1504 & & & 1517 \\
\hline Narruondo, Iñigo de & & & & 1506 & & & \\
\hline $\begin{array}{l}\text { Narruondo, Maestre } \\
\text { Martín de }\end{array}$ & $\begin{array}{l}1503 \\
1513\end{array}$ & & & $\begin{array}{c}1503-1506 \\
1509 \\
1511 \\
1513 \\
\end{array}$ & & & 1517 \\
\hline $\begin{array}{l}\text { Sasiola, Jofre de } \\
\text { (bachiller) }\end{array}$ & 1503 & & & & & & \\
\hline Sasiola, Julián de & & & & 1517 & & & 1517 \\
\hline $\begin{array}{l}\text { Torre, Iñigo Ibáñez } \\
\text { de la }\end{array}$ & $\begin{array}{l}1506 \\
1511 \\
1512 \\
\end{array}$ & & & 1503 & & & \\
\hline $\begin{array}{l}\text { Zumaya, Juan Sánchez } \\
\text { de }\end{array}$ & & & & & 1515 & & \\
\hline $\begin{array}{l}\text { Zumaya, Lope } \\
\text { Fernández de }\end{array}$ & $\begin{array}{l}1510 \\
1516 \\
1517\end{array}$ & 1515 & & $\begin{array}{l}1507 \\
1511 \\
1517\end{array}$ & & & 1517 \\
\hline
\end{tabular}

Fuente: Archivo de la Real Chancillería de Valladolid (ARCHV), Pleitos civiles, Escribanía Zarandona y Balboa, Pleitos Fenecidos, 922/1.

En el caso de Zumaya entre los poseedores de cargos entre 1502 y 1517 encontramos a miembros de linajes como los Arteaga, Dornuategui, Elcano, Elorriaga, Indaneta, Iraeta, Irure, Mirubia, Narruondo, Sasiola, Torre o Zumaya; mientras que en la tierra de Zumaya encontramos a los Mancisidor y Osango. La variedad de situaciones sociales parece importante, aunque en la mayor parte de los casos se trata de personajes vinculados al gobierno concejil y a actividades comerciales -a semejanza de lo que ocurría en la cercana Guetaria ${ }^{20}$-, como los Elcano, dos de cuyos miembros, Juan y Sebastián eran también vecinos concejantes y comerciantes

${ }^{20}$ Donde familias como los Arrona, Guevara, Balda, Amilibia, Segurola y Martínez de Zarauz y sus descendientes controlaban los principales oficios a finales del siglo XV y comienzos del XVI. GARCíA FERNÁNDEZ, E.: "La población de la villa..., 340. 
en Guetaria en $1474^{21}$, y los Zumaya, de entre los que destaca Lope Sánchez de Zumaya escribano fiel en 1515, quien desde 1453 poseía un privilegio de juro de heredad de 12 cargas de trigo sobre las alcabalas de la villa ${ }^{22}$, y Juan Fernández de Zumaya, alcalde de Zumaya en 1510, 1516 y 1517 y procurador síndico en 1515; únicamente en el caso de Fernando de Indo sabemos que era cantero.

La mayor parte de ellos, con anterioridad, posterioridad y durante el desempeño de sus cargos compaginaron su labor y actuaron como procuradores de la villa en las Juntas Generales celebradas durante dicho período. Más aún, tres de ellos, concretamente Antón de Elcano, Lope Fernández de Zumaya y Juan Pérez de Elorriaga, eran además escribanos de la villa, siendo el último, escribano fiel del concejo entre 1516 y 1517 . Precisamente los dos últimos mencionados fueron alcaldes ordinarios en 1510 y 1517, y 1509 y 1515, respectivamente, es decir, repitieron cargo con un intervalo de seis o siete años. Por tanto, todos ellos eran personas plenamente insertadas en la estructura administrativa local; alguno de ellos incluso, como ocurre con Martín Fernández de Dornuategui, formaba parte de un linaje que había participado en la fundación de la villa en 1344: su antepasado Beltrán Ibáñez de Dornuategui participó en el convenio firmado en dicha fecha por los vecinos del lugar de Zumaya con el convento de Roncesvalles ${ }^{23}$.

Por último, algunos de estos linajes urbanos y comerciales emparentaron con linajes de Parientes Mayores. El linaje Zumaya estaba emparentado con el linaje Iraeta, de Parientes Mayores -algunos miembros del linaje (Juan y Pedro Martínez de Iraeta), aunque no podemos precisar a qué rama pertenecían, eran vecinos concejantes-, por medio del matrimonio en fecha desconocida entre María López de Iraeta y el mencionado escribano y alcalde de Zumaya, Lope Fernández de Zumaya. Por su parte, los Arteaga se vincularon a los Alzolaras en el siglo XV: Martín Ibáñez de Arteaga se casó con María Ibáñez de Alzolaras, hija de Juan López de Olazábal, señor de Alzolaras ${ }^{24}$.

Como en el anterior, también en el caso Azpeitia encontramos ciertas sagas y linajes que ocupan de forma reiterada los cargos concejiles entre 1515 y 1520 : Acharan, Alzaga, Arrieta, Egurza, Garagarza, Garín, Izaguirre, Lasao, Lete y Ondarra, algunos de ellos con prolongada presencia en la villa: en 1348 ya aparecen Pero García de Garagarza, Martín Johan de Garagarza y Martín de Garagarza, y en 1352 Martín Ibáñez de Acharan, entre los pobladores de la tierra de Azpeitia que se avecindaron al concejo de Salvatierra de Iraurgi. Posteriormente para la década de los años cuarenta del siglo XVI encontramos a los Acharan emparentados con los Alzaga, importante linaje de mercaderes, puesto que el bachiller Martín Martínez de Acharan se unió a doña Francisca de Alzaga, más que probablemente hermana de Juan de Alzaga, mercader, fiel en 1515 y regidor en 1517 y $1520^{25}$. Las relacio-

21 GUERrA, J.C.: Ensayo de un padrón histórico de Guipúzcoa según el orden de sus familias pobladoras, Joaquín Muñóz-Baroja, Madrid, 1928, 175.

22 Archivo General de Simancas (AGS), EMR, MYP, Leg. 104, fol. 176.

23 odriozola oyarbide, L.: Historia de Zumaya, Zumaiako udala, Zumaia, 1998, 43.

24 Aguinagalde, B.: "La genealogía de los solares..., 173, 177 y 178.

25 MARÍn PARedes, J.A.: "Semejante Pariente Mayor”. Parentesco, solar, comunidad y linaje en la institución de un Pariente Mayor en Gipuzkoa: los señores del solar de Oñaz y Loyola (siglos XIV-XVI), 
nes entre diferentes vecinos concejantes y oficiales concejiles eran estrechas, no sólo estableciendo vínculos familiares y matrimoniales, si no también económicos y de amistad. Domingo de Garagarza presentó como fiador a maestre Juan de Çutola, regidor en 1518. Por su parte, Juan de Ondarra, alcalde ordinario un año antes en 1515, presentó al escribano Juan Martínez de Ibarbia, regidor en 1517 y 1520 , procurador en Juntas Generales en 1517 y 1518, y escribano fiel del concejo en 1518. Finalmente, Pedro de Ondarra presentó por fiador a Juan Pérez de Egurza, escribano fiel en 1519 y fiel del concejo un año después, en 1520. Comprobamos, una vez más, que quienes ostentaban los cargos concejiles eran gentes abonadas y bien situadas económica, social y políticamente.

Tabla 3: oficiales concejiles en Azpeitia (1515-1520)

\begin{tabular}{|c|c|c|c|c|c|c|c|c|c|}
\hline Nombre & $\begin{array}{l}\frac{0}{\tilde{J}} \\
\frac{\mathrm{J}}{2}\end{array}$ & $\Phi$ & 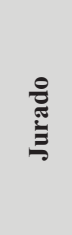 & 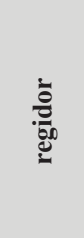 & 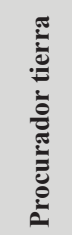 & 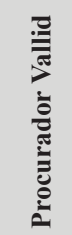 & 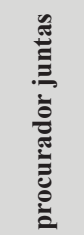 & 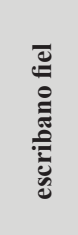 & 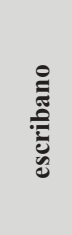 \\
\hline $\begin{array}{l}\text { Acharan, Juan de } \\
\text { (barbero) }\end{array}$ & & & 1518 & & & & & & \\
\hline $\begin{array}{l}\text { Acharan, Juan } \\
\text { Sánchez de }\end{array}$ & & & $\begin{array}{l}1515 \\
1517 \\
\end{array}$ & & & & & & \\
\hline $\begin{array}{l}\text { Alzaga, Juan de } \\
\text { (mercader) }\end{array}$ & & 1515 & & $\begin{array}{l}1517 \\
1520\end{array}$ & & & & & \\
\hline $\begin{array}{l}\text { Alzaga, Juan } \\
\text { Martínez de }\end{array}$ & & 1519 & & & & 1516 & & $\begin{array}{l}1518 \\
1520\end{array}$ & $\begin{array}{l}1517 \\
1518\end{array}$ \\
\hline $\begin{array}{l}\text { Arrieta, Diego } \\
\text { Íñiguez de }\end{array}$ & & & & 1519 & & & & & \\
\hline $\begin{array}{l}\text { Arrieta, Domingo } \\
\text { Ibáñez de }\end{array}$ & 1516 & & & & & & & & \\
\hline Egurza, Domingo & & & & & & 1517 & 1516 & & 1516 \\
\hline $\begin{array}{l}\text { Egurza, Juan } \\
\text { Martínez de }\end{array}$ & & & & & 1520 & & $\begin{array}{l}1515 \\
1516\end{array}$ & 1516 & 1517 \\
\hline $\begin{array}{l}\text { Egurza, Juan } \\
\text { Pérez de }\end{array}$ & & 1520 & & & & & & 1519 & 1520 \\
\hline $\begin{array}{l}\text { Garín, Juan } \\
\text { García de }\end{array}$ & & & & & & & 1519 & & \\
\hline $\begin{array}{l}\text { Garín, Juan } \\
\text { Sánchez de }\end{array}$ & & 1517 & & $\begin{array}{l}1516 \\
1519\end{array}$ & & & 1517 & & \\
\hline $\begin{array}{l}\text { Garín, Pedro } \\
\text { López de }\end{array}$ & 1520 & & & 1516 & & & & & \\
\hline
\end{tabular}

Diputación Foral de Gipuzkoa, San Sebastián, 1998, 73-75 y 257-258. 


\begin{tabular}{|l|l|l|l|l|l|l|l|l|l|}
\hline $\begin{array}{l}\text { Izaguirre, } \\
\text { Domingo de }\end{array}$ & 1519 & & & $\begin{array}{l}1517 \\
1518\end{array}$ & & & & & \\
\hline $\begin{array}{l}\text { Izaguirre, Juan } \\
\text { Ochoa de }\end{array}$ & & & & 1515 & & & & 1516 & 1517 \\
\hline $\begin{array}{l}\text { Izaguirre, Ochoa } \\
\text { Pérez }\end{array}$ & 1517 & & & & & & & & \\
\hline Izaguirre, Pedro de & 1519 & & & & & & 1517 & 1517 & 1517 \\
\hline $\begin{array}{l}\text { Lasao, Juan } \\
\text { Martínez de }\end{array}$ & 1518 & & 1517 & & & 1517 & 1519 & 1520 \\
\hline $\begin{array}{l}\text { Lasao, Juan } \\
\text { Martínez de (de la } \\
\text { plaza) }\end{array}$ & 1517 & & & 1516 & & & & & \\
\hline Lete, Juan Pérez de & 1518 & & & & & & & & \\
\hline Lete, Pedro de & & 1516 & & 1518 & & & & & \\
\hline Ondarra, Juan de & 1515 & & 1516 & & 1519 & & & & \\
\hline Ondarra, Pedro de & & & 1519 & & & & & & \\
\hline
\end{tabular}

Fuente: AMAzp, 774-01.

Aunque la serie de cuentas que se ha conservado en Motrico no es muy prolongada y se reduce a menos de una década, entre 1502 y 1508, las tendencias que se perciben son idénticas a las del resto de casos. Los cargos concejiles aparecen monopolizados por linajes como los Davil de Aguirre, Arteaga, Ferrería, Ibiri -comerciantes con importante presencia en la villa todavía a mediados del siglo $\mathrm{XVI}^{26}{ }_{-}$, Iciar, Leaegi, Meceta, Sasiola o Ubilla. No es mucho lo que sabemos sobre estos linajes y personajes, pero al igual que en los casos precedentes, muchos de ellos eran mercaderes, empresarios pesqueros, escribanos y bachilleres, labores con las que compaginaban sus oficios concejiles. Fue habitual que los cargos oficiales fuesen desempeñados en varios ejercicios consecutivos y que varios cargos fuesen desempeñados por la misma persona. Así Pascual de Arteaga, emparentado con los Ubilla -era tío del escribano Juan de Ubilla-, importante linaje de escribanos y comerciantes, desempeñó el cargo de fiel en tres ejercicios alternos, compaginando en 1506 el cargo de fiel y de bolsero, además del de cogedor de la foguera provincial en 1505 y el de cogedor de la pecha en 1506 y 1507 . En ciertas ocasiones aquellos que detentaron el cargo de alcalde, seis años después volvieron a hacerlo. En todo caso, al menos en cinco ocasiones aquellos que actuaban como alcaldes eran escribanos o bachilleres, es decir, hombres de letras, alfabetizados; únicamente Martín de Bilbao, fiel en 1504 y alcalde en 1505, no sabía escribir y hubo de firmar la aceptación de las cuentas el escribano fiel de turno.

De entre los miembros destacados del concejo de Motrico encontramos a sus vecinos, Jofre Ibáñez de Sasiola, mercader y alcalde de Motrico en 1502 y a Miguel Ibáñez de Sasiola -también vecino de Deva-, patrón de nao y cogedor del repartimiento

\footnotetext{
${ }^{26}$ ARRIETA, L.: Mutriku. Una aproximación a nuestra historia, Ayuntamiento de Mutriku, Mutriku,
} 1996, 104-105. 
en 1507, padre y hermano respectivamente del Bachiller Jofre Ibáñez de Sasiola, vecino de Deva y Elgóibar - en 1503 alcalde de Zumaya-. Jofre Ibáñez, hijo de Íñigo Ibáñez de Sasiola y María Ruíz de Irarrazábal, se casó con María Ibáñez de Oyanguren. Su hijo, el bachiller Jofre Ibáñez de Sasiola, fue miembro del Consejo Real y Embajador en Inglaterra para pactar el matrimonio de doña Catalina de Aragón con el Príncipe de Gales. En recompensa por ambas labores fue nombrado caballero de la orden inglesa de la Jarretera y obtuvo en tierras 7.800 maravedís, situados en las alcabalas de Deva, para cinco lanzas mareantes en $1484^{27}$. Su hijo el tesorero Rodrigo de Sasiola emparentaría a comienzos del siglo XVI con Ana Ibáñez de Iraeta, hermana del señor de Iraeta ${ }^{28}$. Por tanto, los Sasiola extendieron sus tentáculos por toda la cuenca baja del Deva y el sector occidental de la costa guipuzcoana (Elgóibar, Deva, Motrico, Zumaya y Guetaria).

Tabla 4: oficiales concejiles en Motrico (1502-1508)

\begin{tabular}{|c|c|c|c|c|c|c|c|}
\hline Nombre & $\frac{\frac{\pi}{\tilde{J}}}{\frac{\pi}{\pi}}$ & 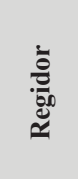 & $\bar{\Xi}$ & 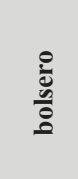 & 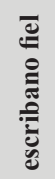 & 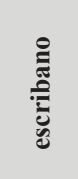 & 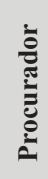 \\
\hline Aguirre, Antón de & & 1505 & & & & & \\
\hline Aguirre, Pedro Davil de & $\begin{array}{l}1502 \\
1508\end{array}$ & 1507 & & & & 1502 & \\
\hline Aguirre, Sancho Davil de & 1518 & & & & & & \\
\hline Arteaga, Domingo de & & 1508 & 1506 & & & & \\
\hline Arteaga, Pascoal & & 1506 & $\begin{array}{l}1504 \\
1506 \\
1508\end{array}$ & 1506 & & & \\
\hline $\begin{array}{l}\text { Astigarribia, Martín } \\
\text { Iñíguez de }\end{array}$ & 1506 & 1507 & & & & & \\
\hline Bilbao, Martín de & 1505 & & 1504 & & & & \\
\hline $\begin{array}{l}\text { Carquizano, Domingo } \\
\text { Ruiz de (Bachiller) }\end{array}$ & 1505 & 1504 & & & & & \\
\hline
\end{tabular}

${ }^{27}$ AGS, RGS, Leg. 148802, 253; AGS, RGS, Leg. 148607, 49; AGS, CMH, EMR, Leg. 1, fol. 45; AGS, CRC, 593, 1; AGS, PTR, Leg. 53, 16; Archivo de la Real Sociedad Bascongada de Amigos del País, Fondo de los Condes de Peñaflorida, Sección Munibe, Arancibia-Sasiola, Transmisión de bienes, 493; HERRERO, V.J., BARRENA OSORO, E.: Archivo Municipal de Deba. I (1181-1520), Eusko Ikaskuntza, San Sebastián, 2005, 126, 143, 153, 174 y 322; HERRERO, V.J., BARRENA, E.: Archivo Municipal de Deba. II. Libro de Apeos y Ventas de Tierras Concejiles (14821483), Eusko Ikaskuntza, San Sebastián, 2005, 21, 24, 34, 35 y 128; AYERBE IRIBAR, M.R., ETXEZARRAGA GABILONDO, J.: Archivo Municipal de Elgoibar (1346-1520), Eusko Ikaskuntza, San Sebastián, 1999, 79-80; ATIENZA Y NAVAJAS, J.: "El mayorazgo de Sasiola, en Deva (Guipúzcoa)", Revista Hidalguía, 1 (1953), 109-112, BARÓN DE COBOS DE BELCHITE: "Linajes de la villa de Deva (Guipúzcoa)", Revista Hidalguía, 31 (1958), 1028-1030; ORELLA UNZUE, J.L.: "Geografias mercantiles vascas en la Edad Moderna (III). Las relaciones vascas con Inglaterra. Siglos XIV-XVI", Lurralde, San Sebastián, 28 (2005), 85-152; GUERRA, J.C.: Ensayo..., 546.

${ }^{28}$ Aguinagalde, B.: "La genealogía de los solares..., 173. 


\begin{tabular}{|l|c|c|c|c|c|c|c|}
\hline Elorreta, Miguel de & $\begin{array}{c}1503 \\
1508\end{array}$ & & & & & & \\
\hline Ferrería, Andrés de la & 1504 & & & & & & \\
\hline Ferrería, Juan Ramos de & 1506 & 1507 & & & & & 1507 \\
\hline Ferrería, Nicolás de & & & & & & & \\
\hline Goytinis, Pedro Ibáñez de & 1507 & 1504 & & & & & \\
\hline Ibiri, Domingo de & & & 1505 & 1505 & & & \\
\hline Ibiri, Juan de & & & 1505 & & & & \\
\hline Içiar, Pascoal de & & 1508 & & & & & \\
\hline Içiar, Pedro de & & & 1504 & 1504 & & & \\
\hline Jausoro, Pedro López de & 1503 & 1504 & & & & & \\
\hline Leaegi, Pascoal de & & & 1508 & & & & \\
\hline Leaegi, Pedro de & & & 1508 & & & & \\
\hline Meceta, Gonzalo & & 1504 & & & & & \\
\hline Meceta, Juan Ibáñez de & & & & & & & \\
\hline Meceta, Pascoal Miguelez de & 1507 & 1505 & & & 1503 & & \\
\hline Olabarrieta, Domingo de & & & 1506 & & & & \\
\hline Portal, Juan Martínez de & & 1506 & & & & & \\
\hline Sarasua, Ochoa de & & 1505 & 1505 & 1505 & & & \\
\hline Sasiola, Jofre Ibáñez de & 1502 & & & & & & \\
\hline Sasiola, Miguel Ibáñez de & & & & & & & \\
\hline Ubilla, Juan & & & 1504 & & & & \\
\hline $\begin{array}{l}\text { Ubilla, Juan San Juan de } \\
\text { (Bachiller) }\end{array}$ & 1504 & & & & & \\
\hline
\end{tabular}

Fuente: herrero, v.J., Fuentes medievales..., 101-209.

Los casos de Villafranca de Ordicia y de Mondragón, a diferencia de los anteriores, cuentan con interesante y abundante documentación que nos permite realizar un análisis más profundo. En Villafranca de Ordicia el monopolio de cargos concejiles por parte de unas pocas familias es ostensible: Amézqueta, Aramburu, Aranguren, Arramendi, Arteaga, Barrena, Berástegui, pero sobre todo Iribe, Isasaga y Mújica copan los principales cargos ya desde el siglo XV hasta 1518, aunque posteriormente aparecerán también familias como los Arza, la mayor parte de las cuales seguirá ocupando cargos concejiles hasta bien entrado el siglo XVIII ${ }^{29}$. Algo similar ocurre en el caso de las vecindades, donde destacan los Aguirre, Ayesta, Barandiarán o Zubiaurre. La inmensa mayoría de los cargos concejiles aparece inscrita en los padrones fiscales entre los pecheros enteros. Aunque algunos nombres desaparecen y otros se incorporan (Lazcano o Arza), prácticamente entre 1506 y 1543 son las mismas personas y familias las que se mantienen en la cúspide social y patrimonial. Observamos que

29 GAldos monfort, A.: De Villafranca a Ordizia. Un camino pleno de historia, Ayuntamiento de Ordizia, Ordicia, 2008, 222. 
la mayoría de ellos, personajes como Martín de Beitia, García López de Iribe, Juan García de Iribe, Pedro Ochoa de Iribe -quien junto a Lope Ochoa, su hijo, y a García Ibáñez de Mújica, estuvo entre los desafiados por los Parientes Mayores en $1456^{30}$, García Álvarez de Isasaga, Martín Álvarez de Isasaga, Pedro Ochoa de Isasaga, Juan Martínez de Miranda, Juan Martínez de Mújica, Juan de San Juan o Juan Miguélez de Ugarte, ya aparecen en 1506 entre los pecheros enteros. Gracias a la estimación o "apreciamiento" de bienes de 1549, podemos conocer el patrimonio y bienes de algunos de ellos, aunque linajes como el de Iribe ya para entonces apareciesen algo decaídos. La mayor parte posee importantes propiedades tanto en la villa como en las vecindades, donde las posesiones realmente alcanzaban valores remarcables, concretamente en Lazcano, Arama, Beasain, Isasondo o Zaldivia: casas en el cuerpo de la villa, caserías, tierras de labor, castañales o molinos. En la mayoría de los casos, los bienes de aquellos que durante el período de estudio ocuparon cargos concejiles superan en 1549 los 1.000 ducados, lo cual es una nueva muestra de la importancia social y económica de nuestros protagonistas.

Tabla 5: oficiales concejiles en Villafranca de Ordicia (1451-1518)

\begin{tabular}{|c|c|c|c|c|c|c|c|c|c|}
\hline Nombre & 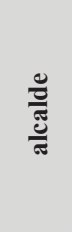 & 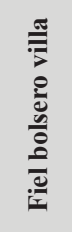 & 产 & 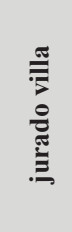 & 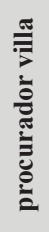 & 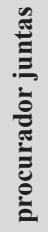 & 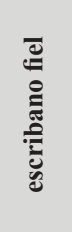 & 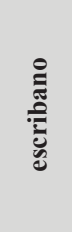 & 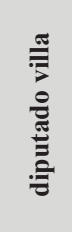 \\
\hline Amézqueta, Juan de & & & & 1505 & & & & & \\
\hline Amézqueta, Martín de & & & & 1488 & & & & & \\
\hline $\begin{array}{l}\text { Aramburu, Juan García } \\
\text { de (Gainza) }\end{array}$ & & & & & & & & & \\
\hline Aramburu, Pascoal de & & & & & & & & & 1451 \\
\hline Aranguren, Juan de & & & & 1507 & & & & & \\
\hline Aranguren, Juan Ochoa de & 1451 & & & & & & & & \\
\hline Aranguren, García de & & & & & & & & & 1451 \\
\hline $\begin{array}{l}\text { Arramendi o } \\
\text { Arranomendia, (San) } \\
\text { Juan o Juan Martínez de }\end{array}$ & & 1501 & & 1512 & & & & 1518 & \\
\hline Arramendi, Miguel de & & & & 1451 & & & & & \\
\hline Arteaga, Juan de & & & & & & & $\begin{array}{l}1505 \\
1507\end{array}$ & $\begin{array}{l}1451 \\
1488\end{array}$ & 1451 \\
\hline Arteaga, Juan Ibáñez de & 1508 & $\begin{array}{l}1470 \\
1491\end{array}$ & & & & & & 1488 & 1451 \\
\hline $\begin{array}{l}\text { Arteaga, Juan Ibáñez de } \\
\text { (sastre) }\end{array}$ & & 1500 & & & & & & & \\
\hline Arteaga, Juan Miguélez de & & 1467 & & & & & & & 1500 \\
\hline
\end{tabular}

30 arízaga bolumburu, B.: Urbanística medieval (Guipúzcoa), Kriselu, San Sebastián, 1990, 222; GALDOS MONFORT, A., De Villafranca a Ordizia..., 211. 


\begin{tabular}{|c|c|c|c|c|c|c|c|c|c|}
\hline Arteaga, Miguel de & & & & 1451 & & & & & \\
\hline Arteaga, Ochoa de & 1501 & 1496 & & & & & & & \\
\hline $\begin{array}{l}\text { Arteaga, Pedro de } \\
\text { (sastre) }\end{array}$ & & & & 1500 & & & & & \\
\hline Barrena, Juan Ochoa de & & & & & & & & & 1451 \\
\hline Barrena, Lope Ochoa de & 1467 & & & & & & & & \\
\hline Barrena, Martín López de & & & & & & & & & 1451 \\
\hline Barrena, Martín Ochoa de & & & & & & & & 1479 & 1451 \\
\hline $\begin{array}{l}\text { Berástegui, Fernand } \\
\text { Pérez de }\end{array}$ & & & & & & & & 1451 & 1451 \\
\hline $\begin{array}{l}\text { Berástegui, Pedro } \\
\text { Ferrández de }\end{array}$ & & 1482 & & & & 1482 & & & \\
\hline Iribe, García López de & 1499 & 1496 & 1492 & & & & & 1499 & \\
\hline Iribe, Juan García de & 1500 & 1488 & & 1507 & & & & & \\
\hline Iribe, Lope Ochoa de & & & & & & & & & 1451 \\
\hline Iribe, Ochoa de & & 1470 & & & & & & & \\
\hline Iribe, Pedro Ochoa de & $\begin{array}{l}1507 \\
1518 \\
\end{array}$ & 1491 & & & 1495 & & 1508 & & 1500 \\
\hline Iribe, Lope García de & 1521 & & & & & & & & \\
\hline Isasaga, García Álvarez de & 1500 & $\begin{array}{l}1463 \\
1507\end{array}$ & & & 1495 & $\begin{array}{l}1488 \\
1507\end{array}$ & 1500 & $\begin{array}{l}1451 \\
1488 \\
1518\end{array}$ & \\
\hline $\begin{array}{l}\text { Isasaga, García Álvarez } \\
\text { de (hijo) }\end{array}$ & $\begin{array}{l}1499 \\
1504\end{array}$ & & & & & & & 1518 & \\
\hline Isasaga, Juan Ibáñez de & 1500 & & & & & & & 1518 & 1482 \\
\hline Isasaga, Juan Ochoa de & 1491 & $\begin{array}{l}1479 \\
1489\end{array}$ & & 1507 & & & 1506 & 1463 & $\begin{array}{l}1482 \\
1500\end{array}$ \\
\hline $\begin{array}{l}\text { Isasaga, Martín Álvarez } \\
\text { de (el mozo) }\end{array}$ & 1512 & 1500 & & & & & & & 1500 \\
\hline $\begin{array}{l}\text { Isasaga, Martín Álvarez } \\
\text { o García de }\end{array}$ & $\begin{array}{l}1476 \\
1482 \\
1492 \\
1505\end{array}$ & 1504 & & 1507 & 1495 & $\begin{array}{l}1482 \\
1488\end{array}$ & & 1488 & \\
\hline Isasaga, Martín García de & & $\begin{array}{l}1482 \\
1505\end{array}$ & & & & & & & \\
\hline Isasaga, Ochoa Martínez de & 1494 & & & & & & & & $\begin{array}{l}1451 \\
1500\end{array}$ \\
\hline Isasaga, Pedro Ochoa de & & $\begin{array}{l}1491 \\
1497 \\
1498 \\
\end{array}$ & & & & & & & 1451 \\
\hline Lazcano, Martín de & & 1491 & & & & & & & \\
\hline $\begin{array}{l}\text { Miranda, Juan de } \\
\text { (Zaldivia) }\end{array}$ & & & & & & & & & \\
\hline Miranda, Juan Martínez de & 1506 & 1505 & & & & & & & 1500 \\
\hline Mújica, García Ibáñez de & 1488 & 1451 & 1492 & & 1495 & & $\begin{array}{l}1481 \\
1495 \\
\end{array}$ & & \\
\hline Mújica, Juan de & & 1478 & & & & & & & 1451 \\
\hline
\end{tabular}




\begin{tabular}{|c|c|c|c|c|c|c|c|c|}
\hline Mújica, Juan Martínez de & & $\begin{array}{l}1497 \\
1499 \\
1507\end{array}$ & & & & & & \\
\hline Mújica, Lope García de & & $\begin{array}{l}1499 \\
1506\end{array}$ & & & & & & 1500 \\
\hline Mújica, Miguel de & & & 1499 & & & & & \\
\hline San Juan, Juan de & $\begin{array}{l}1489 \\
1504\end{array}$ & $\begin{array}{l}1481 \\
1491 \\
1494 \\
1499\end{array}$ & 1507 & 1495 & & & & 1482 \\
\hline Ugarte, Juan Miguélez de & 1496 & $\begin{array}{l}1476 \\
1488 \\
1494 \\
1495 \\
1506\end{array}$ & 1507 & & & 1499 & & 1500 \\
\hline Ugarte, Juan Pérez de & & & & & 1488 & $\begin{array}{l}1489 \\
1499\end{array}$ & & 1500 \\
\hline Urdaneta, Juan Ochoa de & $\begin{array}{l}1511 \\
1518\end{array}$ & 1501 & & & & & & \\
\hline \multicolumn{9}{|l|}{ Zavala, Juan (Legorreta) } \\
\hline $\begin{array}{l}\text { Zavala, Ochoa Martínez } \\
\text { de (bachiller) }\end{array}$ & & 1489 & 1507 & & & $\begin{array}{l}1451 \\
1489 \\
1497\end{array}$ & 1488 & 1500 \\
\hline
\end{tabular}

Fuente: Archivo de la Real Chancillería de Valladolid (ARCHV), Pleitos civiles, Escribanía Zarandona y Balboa, Pleitos Fenecidos, 1294/3, 1295/1 y 1401/1.

Algo similar ocurre con aquellos que ostentaron cargos en representación de las universidades, quienes habitualmente también habían ocupado con anterioridad o lo harían con posterioridad algún cargo en la villa. Generalmente quienes ostentaron estos cargos eran los vecinos más abonados en las universidades. Así por ejemplo, entre aquellos que desempeñaron el cargo de jurado de las universidades, en 1506 encontramos a Martín de Arín entre los pecheros enteros de Ataun, a Francisco de Echeverría entre los pecheros enteros de Legorreta, a Juan de Echeverría entre los pecheros enteros de Isasondo, a Miguel de Garitano o Garicano como pechero entero en Legorreta, a Martín de Urrutia entre los pecheros enteros de Alzaga o a Juan de Yarza entre los pecheros enteros de Beasain. El patrimonio de la mayor parte de ellos superaba los 1.000 ducados de valor en 1549: así el patrimonio de los Echeverría en Isasondo alcanzaba los 1.000 ducados, el de los Urrutia en Alzaga los 1.230 ducados y el de los Garitano en Legorreta los 2.300 ducados. 
Tabla 6: Estimación de los bienes de vecinos concejantes en Villafranca de Ordicia, 1549 (ducados)

\begin{tabular}{|l|c|c|c|c|c|c|}
\hline \multicolumn{1}{|c|}{ Nombre } & Villafranca & Lazcano & Arama & Isasondo & Zaldivia & TOTAL \\
\hline $\begin{array}{l}\text { Juan Ibáñez de } \\
\text { Arteaga }\end{array}$ & 337 & & & & & 337 \\
\hline García López de Iribe & 30 & & & & & 30 \\
\hline $\begin{array}{l}\text { García Álvarez de } \\
\text { Isasaga }\end{array}$ & 2.083 & & 120 & & 1.160 & 3.363 \\
\hline Comendador Isasaga & 925 & 77 & & 5.700 & & 6.702 \\
\hline $\begin{array}{l}\text { Juan Ibáñez de } \\
\text { Isasaga }\end{array}$ & 1.450 & & & & & 1.450 \\
\hline $\begin{array}{l}\text { Juan Martínez de } \\
\text { Miranda }\end{array}$ & 400 & & & & 7.000 & 7.400 \\
\hline $\begin{array}{l}\text { Juan Ochoa de } \\
\text { Urdaneta }\end{array}$ & 1.237 & & & & & 1.237 \\
\hline
\end{tabular}

Fuente: ARCHV, Pleitos civiles, Zarandona y Balboa, Pleitos Fenecidos, 1401/1.

Para muchos el paso por los concejos fue un trampolín para instancias superiores, bien provinciales bien cortesanas. Entre los miembros de la familia Mújica destaca sobre todo Martín de Mújica, maestresala de la reina Isabel la Católica y posteriormente de la reina Juana, comendador de la orden de Santiago, contador mayor de cuentas, miembro del Consejo real y gobernador de Chile hacia 1515, quien a cambio de sus servicios obtuvo y fundó mayorazgo en 1515 en Villafranca. Casado en 1509 con Francisca de Lazcano, tuvo un único hijo, asimismo llamado Martín de Mújica y Lazcano, quien en 1534 casó con María de Guevara, miembro de la poderosa familia Guevara, bien asentada en la corte de Carlos I. El hijo de ambos, también llamado Martín, participó como procurador de la provincia durante el debate sobre las aduanas, hidalguía y el diezmo viejo. El resto de hijos del matrimonio se unió matrimonialmente con otros linajes de Ordicia, como los Isasaga y Arteaga ${ }^{31}$. Otros miembros destacados fueron: el hermano de Martín de Mújica, Lope García de Mújica, contino del rey Fernando el Católico y maestresala de la reina Juana y veedor de campo en Italia y teniente de su hermano, quien ejerció de alcaide y capitán de la milicia en Fuenterrabía en 1506; el licenciado García Ibáñez

31 galdos monfort, A.: De Villafranca..., 223-225; GOROSABEL, P.: Diccionario HistóricoGeográfico-Descriptivo de los Pueblos, Valles, Partidos, Alcaldías y Uniones de Guipúzcoa, Imprenta de Pedro Gurruchaga, Tolosa, 1862, 620; ARAGÓN RUANO, A.: "Resistencia frente a los nuevos ricos en la Guipúzcoa del siglo XVIII: hidalguía y dificultades en el retorno de los indianos a través del caso de los Marqueses de Torre Tagle", IV Seminario Euskal Herria Mugaz Gaindi, 2009, edición en línea(http:// www.euskosare.org/komunitateak/ikertzaileak/ehmg/4/ponentziak/Itzultzeak/resistencia_nuevos_ ricos_guipuzkoa_siglo_18). 
de Mújica ${ }^{32}$, escribano del número y, entre otros cargos, fiel bolsero en 1451 y alcalde en 1488, quien fue colegial del colegio viejo de San Bartolomé de Salamanca, oidor del consejo real y de cámara, del consejo de los Reyes Católicos y de la reina Juana, y fundó el mayorazgo de los Mújica en Ávila, antes de su muerte en 1520; Juan Martínez de Mújica, fiel bolsero en 1499 y 1507, maestresala de la por entonces princesa Juana ${ }^{33}$.

En la familia Isasaga, cuyo solar originario se situaba en Isasondo, destacó sin duda el hijo de Martín Álvarez de Isasaga, el comendador de la orden de Santiago Ochoa Álvarez o Martínez de Isasaga, alcalde en 1495, quien se emparentó con la familia Miranda, también vecina de Villafranca, a través del matrimonio con María Ruiz de Miranda, y fundó mayorazgo en 1543. Antes, en 1498, a cambio de sus servicios, recibió una merced vitalicia de los derechos pertenecientes a la corona en la explotación del hierro y otros metales de las minas de "Reoyondo" y posteriormente un juro por valor de $40.000 \mathrm{mrs}^{34}$. Entre 1500 y 1509 fue tesorero y secretario de la reina María de Portugal, hija de los Reyes Católicos, tras trabajar a las órdenes del secretario de éstos, Miguel Pérez de Almazán ${ }^{35}$. El 2 de abril de 1509 recibió de Fernando el Católico el título de factor de la Casa de Contratación de Sevilla ${ }^{36}$, cargo que desempeñó hasta 1514 , momento en el que volvió a Villafranca de Ordicia. Desde ese momento y a lo largo de los años veinte lo encontramos representando a la provincia de Gipuzkoa en Vallladolid y la Corte. A pesar de ser uno de los condenados a muerte por el corregidor Acuña, debido a su temprana participación junto al grupo de Hernani -en 1516 actuó como delegado provincial en la armada que fue a Flandes-, en 1529 fue uno de los letrados nombrados por la provincia para llevar a cabo la recopilación de ordenanzas de $1529^{37}$. Otro de los miembros importantes fue el comendador de Rodas don Pedro Ochoa de Isasaga -fiel bolsero en Villafranca de Ordicia los años 1491, 1497 y 1498-, hombre de confianza de Fernando el Católico quien, en 1507, a la muerte de León Pinedo, jurado de la ciudad de Sevilla, fue nombrado para sustituírle como Juez oficial, señalándosele en 1515100.000 reales y posteriormente actuó como Juez de residencia de los oficiales reales en Indias ${ }^{38}$.

\footnotetext{
32 A su muerte, en 1502 ocupó su escribanía pública su nieto Juan Ibáñez de Mújica. AGS, RGS, 1502-XII.

33 AGS, Consejo de Hacienda, Leg. 891; MúGICA ZIFIRIA, S.: "Geografía de Guipúzcoa", Geografía General del País Vasco-Navarro, vol. 5, Alberto Martín, Barcelona, 1918, 994.

34 Archivo General de Simancas (AGS), RGS, Leg, 149802,1 y CME, 100, 129; PIDAL, M., SALVA, M.: Colección de documentos inéditos para la Historia de España, Tomo XXV, Imprenta de la Viuda de Calero, Madrid, 1854, 430-434.

35 Archivo Provincial Histórico de la Comunidad de los Padres Franciscanos, Convento de Zarauz, Obras curiosas, Cajón XIV, 2.

36 Archivo General de Indias, Contratación, 5784, L.1, fols. $10 v^{0}-13 r^{\circ}$ e Indiferente, 1961, L.1, fols. $127 \mathrm{v}^{\mathrm{o}}-129 \mathrm{r}^{\circ}$.

${ }^{37}$ IRIJOA CORTÉS, I.: Gipuzkoa, "so color de Comunidad". Conflicto político y constitución provincial a inicios del siglo XVI, Diputación Foral de Gipuzkoa, San Sebastián, 2006 (edición en línea), 237-238, 245-246.

38 LAgUARDIA TRÍAS, R.A.: El predescubrimiento del Río de la Plata por la expedición portuguesa de 1511-1512, Junta de Investigaçoes de Ultramar, 1973, 52; LAREDO QUESADA, M.A.: Las Indias de Castilla en sus primeros años. Cuentas de la Casa de la Contratatación (1503-1521), Comité Español de
} 
Por último, como ocurría en los casos anteriores, también se constata que muchos de estos linajes urbanos de Villafranca de Ordicia emparentaron con linajes de Parientes Mayores del entorno y del resto de la provincia. Así García Álvarez de Isasaga casó con María Belaz de Elduayen, miembro del linaje Elduayen de San Sebastián, vinculado para entonces con los Engómez y los Amézqueta, cabeza del bando oñacino ${ }^{39}$, lo cual explicaría porqué posteriormente, en 1528, Juan de Isasaga, junto a Juan Ochoa de Urdaneta, también vecino de Villafranca de Ordicia, aparece como tutor de Juan López de Amézqueta, señor de Amézqueta, Yarza y Alzaga, ante el escribano García de Isasaga ${ }^{40}$. También en el linaje Iribe, en el siglo XV, Juan Ochoa de Iribe estuvo casado con Gracia Sánchez de Iraeta, mientras que Sancha Ochoa de Iribe lo estuvo con el Bachiller Juan Martínez de Olano y Lope Ochoa de Iribe con María García de Yarza, emparentando así con los Amézqueta ${ }^{41}$.

En Mondragón, los cargos concejiles estuvieron en manos de miembros de familias como los Abarrategui, Albistur, Alzarte, Arcarazo, Aroca, Báñez de Artazubiaga, Cuadra, Olariaga, Oro, Ozaeta o Urrupain, las más principales de la villa de Mondragón, mercaderes, bachilleres, escribanos y hombres de letras y leyes, personas con un alto nivel económico. Muestra de ello, es el hecho de que en el año 1512, seguramente para hacer frente a los gastos derivados de la Conquista de Navarra y de la Armada enviada a Inglaterra, el concejo de Mondragón se vió obligado, como ya había hecho en 1501, a vender ciertos montes concejiles en Arranbiscar y tierras y solares en Gazteluondo y Serualde, que fueron comprados por muchos de los mencionados linajes ${ }^{42}$. Sin duda alguna, la familia mejor conocida, gracias a los trabajos de Achón Insausti, es la de los Báñez de Artazubiaga. Así Asencio Báñez de Artazubiaga, Juan Báñez de Artazubiaga y Martín Báñez de Artazubiaga ocuparon diferentes cargos entre 1501 y 1519. El linaje parece proceder de la cercana aldea de Bedoña, del que hubieron de huir, ante el acoso de los Guevara, a pesar de que hasta 1353 no encontramos al primer Artazubiaga en Mondragón: se trata del escribano Martín Ibáñez de Artazubiaga, quien desde su llegada a Mondragón convirtió su linaje en un grupo de poder. Fue su hijo Juan el que cambió el patronímico Ibáñez por Báñez. El origen de la riqueza del linaje parece estar en el comercio del hierro y el acero, al que se dedicaron tanto Ochoa Báñez como su hijo Martín Báñez de Artazubiaga, que aparecen en la documentación como mercaderes. Su destino principal fue la adquisición de bienes raíces, pues durante los siglos XIV y XV habían obtenido y ampliado su patrimonio a través de dotes, compras o subastas de deudas, que les situaron en la cúspide patrimonial de la villa, contando entre sus bienes con solares, caserías, manzanales, tierras de labor, montes, ganado, veneras, ferrerías y molinos, tanto intramuros como extramuros.

Ciencias Históricas, Madrid, 2008; MÚGICA ZUFIRIA, s.: "Geografía de Guipúzcoa..., 308; AGI, Patronato, 174, R 23 y 176, R 13 e Indiferente, 418, L.8, fols. $26 \mathrm{v}^{\mathrm{o}}-28 \mathrm{v}^{\mathrm{o}}, 30 \mathrm{r}^{\mathrm{o}} \mathrm{y} \mathrm{v}^{\mathrm{o}}, 66 \mathrm{v}^{\mathrm{o}}-67 \mathrm{r}^{\mathrm{o}}, 246 \mathrm{r}^{\mathrm{o}} \mathrm{y} \mathrm{v}^{\mathrm{o}}$.

${ }^{39}$ Aguinagalde, B.: "La genealogía de los solares..., 181.

40 Archivo Histórico de Loyola de los P.P. Jesuitas, Familia Loyola y enlazados, 0001/015.

${ }^{41}$ aguinagalde, B.: "La genealogía de los solares..., 173, 185 y 190.

${ }^{42}$ Este fenómeno también es puesto de manifiesto por achón InSAUSTI, J.A.: " $A$ voz de concejo..., 290. 
Tabla 7: oficiales concejiles en Mondragón (1500-1520)

\begin{tabular}{|c|c|c|c|c|c|c|c|c|c|}
\hline Nombre & $\frac{\frac{0}{\frac{V}{J}}}{\frac{\text { J }}{4}}$ & 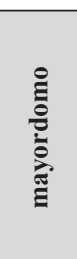 & 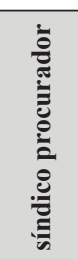 & 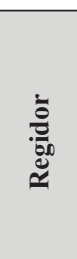 & 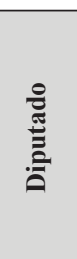 & 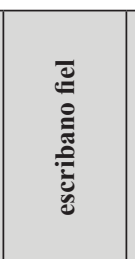 & 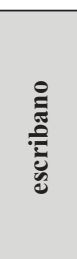 & 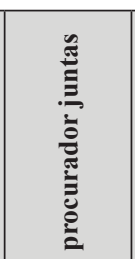 & 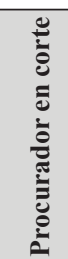 \\
\hline $\begin{array}{l}\text { Abarrategui, } \\
\text { Juan Pérez de }\end{array}$ & & & & & & & 1518 & & \\
\hline $\begin{array}{l}\text { Abarrategui, } \\
\text { Pedro Ochoa de }\end{array}$ & & & & $\begin{array}{l}1505 \\
1506\end{array}$ & $\begin{array}{l}1510 \\
1517\end{array}$ & $\left|\begin{array}{c}1512-1515 \\
1518\end{array}\right|$ & $\begin{array}{l}1511 \\
1517 \\
1520\end{array}$ & $\begin{array}{l}1511 \\
1517 \\
1518 \\
1520\end{array}$ & \\
\hline $\begin{array}{l}\text { Albistur, Martín } \\
\text { Ochoa de }\end{array}$ & & 1519 & & 1511 & $\begin{array}{l}1503 \\
1511 \\
1513 \\
\end{array}$ & & & & \\
\hline Albistur, Pedro de & & & & & 1520 & & & & \\
\hline $\begin{array}{l}\text { Albistur, Rodrigo } \\
\text { de }\end{array}$ & & & & $\begin{array}{l}1509 \\
1516\end{array}$ & $\begin{array}{l}1511 \\
1513 \\
\end{array}$ & & & & \\
\hline $\begin{array}{l}\text { Alzarte, Juan } \\
\text { López de }\end{array}$ & & & & & & $\begin{array}{l}1516 \\
1517 \\
1519 \\
\end{array}$ & 1519 & & $\begin{array}{l}1511 \\
1514\end{array}$ \\
\hline $\begin{array}{l}\text { Alzarte, Lope } \\
\text { Ibáñez de }\end{array}$ & & & & 1501 & 1503 & & & $\begin{array}{l}1501 \\
1502\end{array}$ & \\
\hline $\begin{array}{l}\text { Arcarazo, Juan } \\
\text { López de }\end{array}$ & $\begin{array}{l}1511 \\
1513 \\
1514 \\
\end{array}$ & & & & 1510 & 1507 & $\begin{array}{l}1510 \\
1511\end{array}$ & $\begin{array}{c}1501-1505 \\
1515\end{array}$ & 1510 \\
\hline $\begin{array}{l}\text { Arcarazo, Lope } \\
\text { García de }\end{array}$ & & & & & & 1502 & & & \\
\hline \multicolumn{10}{|l|}{ Aroca, Juan de } \\
\hline $\begin{array}{l}\text { Aroca, Martín } \\
\text { Ochoa de }\end{array}$ & & & & 1518 & $\begin{array}{l}1513 \\
1516 \\
\end{array}$ & & & & \\
\hline $\begin{array}{l}\text { Artazubiaga, } \\
\text { Asencio Báñez de }\end{array}$ & & $\begin{array}{l}1509 \\
1517 \\
\end{array}$ & $\begin{array}{l}1513 \\
1515\end{array}$ & & $\begin{array}{l}1501 \\
1511 \\
\end{array}$ & & & & \\
\hline $\begin{array}{l}\text { Artazubiaga, } \\
\text { Juan Báñez de }\end{array}$ & & & & & 1519 & & & & \\
\hline $\begin{array}{l}\text { Artazubiaga, } \\
\text { Martín Báñez de }\end{array}$ & $\begin{array}{l}1505 \\
1510 \\
\end{array}$ & & & & & & & & \\
\hline $\begin{array}{l}\text { Cuadra, Juan } \\
\text { Ochoa de la } \\
\end{array}$ & 1501 & & 1504 & & 1505 & & & & \\
\hline $\begin{array}{l}\text { Cuadra, Martín } \\
\text { García de la }\end{array}$ & & & 1516 & & & & & & \\
\hline Estella, Jorge de & & & & & & & & & 1517 \\
\hline $\begin{array}{l}\text { Estella, Juan } \\
\text { Fernández de }\end{array}$ & & & & & & & & 1513 & \\
\hline $\begin{array}{l}\text { Estella, Martín } \\
\text { Ibáñez de } \\
\text { (bachiller) }\end{array}$ & $\begin{array}{l}1502 \\
1506 \\
1512 \\
\end{array}$ & & & & & & & & \\
\hline $\begin{array}{l}\text { Gabiria, Juan } \\
\text { García de }\end{array}$ & & & & & 1520 & & & & \\
\hline
\end{tabular}




\begin{tabular}{|c|c|c|c|c|c|c|c|c|}
\hline $\begin{array}{l}\text { Gabiria, Pedro } \\
\text { García de }\end{array}$ & & $1503-1504$ & 1503 & $\begin{array}{l}1500 \\
1514\end{array}$ & & & & \\
\hline $\begin{array}{l}\text { Guesalibar, Juan } \\
\text { Sánchez de }\end{array}$ & & & & 1500 & & & & \\
\hline $\begin{array}{l}\text { Guesalíbar, } \\
\text { Martín Ximénez }\end{array}$ & & 1512 & & & & & & \\
\hline $\begin{array}{l}\text { Guesalibar, Pedro } \\
\text { Sánchez de }\end{array}$ & & 1506 & & $\begin{array}{l}1502 \\
1511 \\
1512\end{array}$ & 1505 & & & \\
\hline $\begin{array}{l}\text { Heduy, Pedro } \\
\text { Ochoa de }\end{array}$ & & & & 1520 & 1513 & & & \\
\hline $\begin{array}{l}\text { Heduy, Pedro } \\
\text { Ruiz de }\end{array}$ & & & & 1519 & & 1500 & & \\
\hline $\begin{array}{l}\text { Ibarra } \\
\text { (licenciado) }\end{array}$ & & & & & & & & 1511 \\
\hline $\begin{array}{l}\text { Ibarra, Juan } \\
\text { Sánchez de }\end{array}$ & & & & 1500 & & & & \\
\hline $\begin{array}{l}\text { Ibarra, Pedro } \\
\text { Martínez de }\end{array}$ & & & & & 1520 & & & \\
\hline $\begin{array}{l}\text { Insaurbe, Juan } \\
\text { Ibáñez de }\end{array}$ & & & & & & & 1516 & \\
\hline $\begin{array}{l}\text { Insaurbe, Ochoa } \\
\text { Ibáñez de }\end{array}$ & & & & $\begin{array}{l}1506 \\
1510 \\
1511 \\
1516 \\
\end{array}$ & & & $\begin{array}{l}1511 \\
1516 \\
1517 \\
1520 \\
\end{array}$ & \\
\hline $\begin{array}{l}\text { Olalde, Antón } \\
\text { Ruiz de }\end{array}$ & 1515 & & & $\begin{array}{l}1512 \\
1513 \\
\end{array}$ & & & & \\
\hline $\begin{array}{l}\text { Olalde, Pedro } \\
\text { Ruiz de }\end{array}$ & & & & 1515 & $\begin{array}{l}1510 \\
1518 \\
\end{array}$ & & & \\
\hline $\begin{array}{l}\text { Olariaga, Juan } \\
\text { Ochoa de }\end{array}$ & & & $\begin{array}{l}1505 \\
1507\end{array}$ & 1506 & & & & \\
\hline $\begin{array}{l}\text { Olariaga, Pedro } \\
\text { Ochoa (menor en } \\
\text { días) }\end{array}$ & & 1514 & & 1519 & & & & \\
\hline $\begin{array}{l}\text { Olariaga, } \\
\text { Pedro Ochoa } \\
\text { de (el mayor) } \\
\text { (mercader) }\end{array}$ & & $\begin{array}{l}1505 \\
1515\end{array}$ & 1518 & $\mid \begin{array}{c}1509-1511 \\
1513-1515 \\
1518 \\
1520\end{array}$ & $\begin{array}{l}1501 \\
1511 \\
1517\end{array}$ & & & \\
\hline $\begin{array}{l}\text { Oro, Domingo } \\
\text { Pérez de }\end{array}$ & & & 1517 & & & & & \\
\hline Oro, Jorge de & & & & & 1505 & $\begin{array}{l}1507 \\
1514\end{array}$ & $\begin{array}{l}1516 \\
1519\end{array}$ & \\
\hline Oro, Lope Ochoa de & & & & $\begin{array}{r}1513 \\
1514 \\
\end{array}$ & & & & \\
\hline $\begin{array}{l}\text { Oro, Martín } \\
\text { López de }\end{array}$ & 1518 & $\begin{array}{l}1501 \\
1502\end{array}$ & & $\begin{array}{l}1504 \\
1515\end{array}$ & $\begin{array}{l}1503 \\
1506 \\
1510 \\
1517 \\
\end{array}$ & & \begin{tabular}{|c|}
$1503-1505$ \\
$1510-1512$ \\
1516 \\
1517 \\
\end{tabular} & \\
\hline $\begin{array}{l}\text { Oro, Pedro } \\
\text { García de }\end{array}$ & & & & & 1504 & & 1503 & \\
\hline $\begin{array}{l}\text { Orozco, Lope } \\
\text { Sánchez de }\end{array}$ & & & & $\begin{array}{l}1501 \\
1514 \\
1517 \\
1518\end{array}$ & $\begin{array}{l}1504 \\
1506 \\
1511\end{array}$ & & $\begin{array}{l}1504 \\
1515 \\
1516 \\
1518 \\
1520\end{array}$ & \\
\hline
\end{tabular}




\begin{tabular}{|c|c|c|c|c|c|c|c|c|c|}
\hline Orozco, Martín de & & & & 1504 & & & & & \\
\hline $\begin{array}{l}\text { Orozco, Pedro } \\
\text { Martínez de } \\
\end{array}$ & & & & 1505 & 1506 & & & $\begin{array}{l}1502 \\
1507 \\
\end{array}$ & \\
\hline $\begin{array}{l}\text { Orozco, Pedro } \\
\text { Sánchez de }\end{array}$ & & & & $\begin{array}{l}1500 \\
1503 \\
1504 \\
\end{array}$ & & & & & \\
\hline $\begin{array}{l}\text { Otalora, Juan } \\
\text { Martínez de }\end{array}$ & & & & & 1517 & & & & \\
\hline $\begin{array}{l}\text { Otalora, Pedro } \\
\text { Ibáñez de }\end{array}$ & & & 1518 & $\begin{array}{l}1505 \\
1506 \\
\end{array}$ & 1501 & & & 1502 & \\
\hline $\begin{array}{l}\text { Salinas, Juan } \\
\text { García de }\end{array}$ & & & & & & 1520 & 1517 & & \\
\hline $\begin{array}{l}\text { Salinas, Martín } \\
\text { Juan de }\end{array}$ & & & & & 1503 & $\begin{array}{l}1501 \\
1502 \\
1505 \\
1515 \\
\end{array}$ & 1511 & & \\
\hline $\begin{array}{l}\text { Salinas, Martín } \\
\text { Ochoa de } \\
\text { (pelejero) }\end{array}$ & & & & & & & & 1504 & \\
\hline $\begin{array}{l}\text { Salinas, Pedro } \\
\text { Pérez de }\end{array}$ & & & & 1500 & & & & & \\
\hline $\begin{array}{l}\text { Santamaría, } \\
\text { Blas de }\end{array}$ & & 1510 & & & & & & & \\
\hline $\begin{array}{l}\text { Santamaría, } \\
\text { Martín Ochoa de }\end{array}$ & 1504 & & & & & & & & \\
\hline $\begin{array}{l}\text { Santamaría, } \\
\text { Pedro Ochoa de }\end{array}$ & & 1516 & $\begin{array}{l}1511 \\
1520 \\
\end{array}$ & & $\begin{array}{l}1504 \\
1519 \\
\end{array}$ & & & 1505 & 1515 \\
\hline Urrupain, Lope & & & & & $\begin{array}{l}1504 \\
1506 \\
1510 \\
1516\end{array}$ & & & & \\
\hline $\begin{array}{l}\text { Urrupain, Martín } \\
\text { Pérez de }\end{array}$ & & $\begin{array}{l}1500 \\
1515\end{array}$ & 1519 & & 1518 & $\begin{array}{l}1504 \\
1510 \\
1512 \\
1513 \\
\end{array}$ & 1520 & & \\
\hline Vergara, Andrés de & & & & 1502 & & & & & \\
\hline $\begin{array}{l}\text { Vergara, } \\
\text { Francisco de }\end{array}$ & & & & & & & & & \\
\hline $\begin{array}{l}\text { Vergara, Juan } \\
\text { Ochoa de }\end{array}$ & & & & & & & & 1511 & \\
\hline $\begin{array}{l}\text { Vergara, Juan } \\
\text { Pérez de } \\
\text { (bachiller) }\end{array}$ & 1513 & & & & & & & $\begin{array}{l}1510 \\
1511 \\
1516 \\
1517\end{array}$ & \\
\hline $\begin{array}{l}\text { Vergara, Ochoa } \\
\text { Pérez de }\end{array}$ & 1519 & & & & 1513 & & & & \\
\hline $\begin{array}{l}\text { Vergara, Pedro } \\
\text { López de }\end{array}$ & & $\begin{array}{l}1502 \\
1518\end{array}$ & & $\begin{array}{l}1512 \\
1513\end{array}$ & $\begin{array}{l}1505 \\
1515\end{array}$ & & & & \\
\hline
\end{tabular}

Fuente: lema pueyo, J.A., GÓmez lago, J.M.: Archivo Municipal de Mondragón. Tomo IV, etc., 1-240 y achón Insausti, J.A.: “A voz de concejo, etc., 258-301. 
Ya para entonces existía una clara división de los oficios concejiles entre los bandos, al menos hasta 1422, fecha en la que los Báñez entran en el bando gamboíno, junto con otros miembros de la élite de la villa: Juan Báñez de Artazubiaga, Pedro Sánchez de Orozco, Pedro Martínez de Orozco o Lope Ibáñez de Olabarrieta. Frente a este bando, los Guraya u oñacinos estarían encabezados por los Oro y Avendaño ${ }^{43}$. Junto a ellos, en los enfrentamientos entre ambos bandos aparecen familias como Arrazola, Vidaur, Ciorrola, Osinaga, Olabarrieta, Cuadra u Orozco, permanentemente presentes en los cargos concejiles durante las primeras décadas del siglo XVI. Por tanto, muchos de los oficiales concejiles tuvieron un pasado banderizo y estuvieron presentes en la dirección de la villa de Mondragón desde al menos el siglo XIV. En palabras de Achón Insausti, “...no hay enfrentamiento claro en esa época entre señores banderizos externos y villa en bloque, sino que son los que controlan la designación de oficiales los mismos que entran en las clientelas banderizas..."44. Todos estos linajes mencionados eran los más pudientes y abonados de la villa y su jurisdicción, como demuestra el empadronamiento de vecinos realizado en 1535. Al frente de la lista estaría Pedro Ochoa de Ozaeta, seguido por Pedro López de Vergara, Asencio Báñez de Artazubiaga, Pedro de Santamaría, Jorge Martínez de Urrupain, Domingo Martínez de Orbe, Francisco Ibáñez de Oro, Martín Ruíz de Otalora, Ochoa Báñez de Artazubiaga, Juan López de Alzarte, Jorge López de Oro, Juan López de Arcarazo y Juan Ochoa de Avendaño, quienes superan los $500.000 \mathrm{mrs}$ de renta ${ }^{45}$. Muchos de ellos eran mercaderes, generalmente vinculados al comercio de hierro y acero, que controlaban gracias a la propiedad de ferrerías, y escribanos, que contaban con una importante liquidez, puesto que en la mayoría de los casos era el dinero el valor más importante de sus bienes, por encima del $50 \%$, aunque paulatinamente lo fueron invirtiendo en la compra de bienes raíces, que finalmente vincularon por medio de la institución de mayorazgos ${ }^{46}$. A pesar de que un $57 \%$ de los vecinos de Mondragón cumplía el requisito mínimo en lo que se refiere a millares (de media suerte) para ocupar cargos concejiles, únicamente un $23 \%$ accedió a cargos concejiles entre 1490 y 1550; de ellos el $81 \%$ vivía intramuros, ocupando el $89^{\prime} 5 \%$ de los $\operatorname{cargos}^{47}$.

${ }^{43}$ Sobre el linaje de los Avendaño, Parientes Mayores gamboínos con presencia sobre todo en Vizcaya y Álava, uno de cuyos miembros, Pedro de Avendaño, junto a Pedro Vélez de Guevara, señor de Oñate, previamente enfrascados en diversas luchas con los Butrón-Múgica en torno a Aramayona y Ochandiano, en la frontera entre los tres territorios vascos, fue uno de los causantes de la quema en 1448 de la villa de Mondragón, véase GARCíA FERNÁNDEZ, E.: "El linaje Avendaño: causas y consecuencias de su ascenso social en la Baja Edad Media", Anuario de Estudios Medievales, 37 / 2 (julio-diciembre 2007), 527-561.

${ }^{44}$ ACHÓN INSAUSTI, J.A.: “A voz de concejo..., 89-102, 133-147.

${ }^{45}$ Ibidem, 276-277.

46 Ibidem, 274-287.

47 Ibidem, 291-295. Este autor habla de ejemplos claros de un relevo de familias en el concejo, pero lo cierto es que algunos de los linajes que considera nuevos, ya venían apareciendo entre 1500 y 1520. Algo muy similar ocurre en el caso de Durango, donde la calle del Medio es donde buena parte de los oficiales concejiles concentraba sus habitaciones y propiedades, quienes normalmente poseían más de una propiedad en la villa. VITORES CASADO, I.: "Durango y sus gentes a través del impuesto. Repartimientos, libros de estimas y fogueraciones como fuentes para el estudio de la sociedad urbana en la baja Edad Media", Sancho el Sabio, Vitoria-Gasteiz, 31 (2009), 34. 
A pesar de los conflictos, o incluso quizás por ello, las relaciones entre las elites de Mondragón fueron fluídas, generalmente a través del matrimonio. Los Báñez de Artazubiaga se unieron matrimonialmente a los Orozco y a los Echavarria. Así Pascuala Martínez de Artazubiaga casó con Pedro Sánchez de Orozco y Marina Martínez de Artazubiaga hizo lo propio con Martín Ochoa de Echavarría, de cuya unión concibieron a Juan Ochoa de Echavarría. No obstante, para el establecimiento de relaciones no siempre tenía porqué mediar consanguineidad, pues los Báñez de Artazubiaga tuvieron intensos tratos con los Olabarrieta y los Osinaga, que participaron con el bando Báñez en la quema de la villa de Mondragón y en otra serie de episodios de la guerra de bandos. Acompañaron así mismo a los Báñez en pleitos y disputas, actuando como testigos o firmantes de contratos. También los Olariaga estuvieron en la órbita de los Báñez de Artazubiaga, no obstante, y a pesar de haber estado presentes en la quema de la villa de Mondragón, protagonizaron, junto a los Estella, las protestas contra el cabeza de bando ${ }^{48}$. Tras la abolición banderiza, ocuparon una preeminente posición social y política, precisamente dos de los protagonistas de la protesta de 1488: Juan Ochoa de Olariaga y Pedro Ochoa de Olariaga, éste segundo mercader, y un tercer Pedro Ochoa de Olariaga, el menor, sumaron 35 puestos concejiles en la primera mitad del siglo XVI. Con anterioridad a 1490, los Olariaga únicamente aparecen constatados cuatro veces en puestos concejiles, lo que prueba que esta familia fue una de las principales beneficiadas de la abolición de los bandos. Pero quizás la vinculación que más llama a priori la atención es la que mantenían los Báñez de Artazubiaga con los Guevara, una de cuyas máximas muestras es la participación de numerosos miembros del linaje en la quema de Mondragón, siguiendo al Guevara. El propio señor de Guevara actuaba como juez árbitro en los pleitos que se suscitaron dentro del propio bando-linaje ${ }^{49}$.

Tabla 8: Cargos Concejiles ocupados por los Báñez en los siglos XIV y XVI

\begin{tabular}{|c|c|c|c|c|c|c|c|}
\hline Nombre & $\frac{\frac{\pi}{\frac{\pi}{J}}}{\frac{\mathrm{e}}{4}}$ & 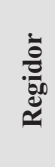 & 总 & 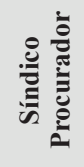 & 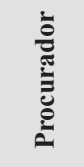 & 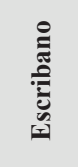 & \\
\hline Martín Ibáñez & & & & & $\begin{array}{l}1389 \\
1396\end{array}$ & 1352 & \\
\hline Martín Báñez I & $\begin{array}{l}1451 \\
1454 \\
1458\end{array}$ & & & & & & \\
\hline
\end{tabular}

48 Entre los opuestos al cabeza de bando encontramos nombres y apellidos que aparecen en la tabla 7: Bachiller Martín Ibáñez de Estella, Juan Martínez de Arteta, Pedro Ibáñez de Otalora, Lope de Urrupain , Martín de Arteta, Pedro Ochoa de Olariaga, Martín de Uncilla, Sebastián López de Soraiz, Juan de Uncilla, Ochoa Martínez de Arteta, el mozo, Lope de Arana, Pedro de Goxendi, Mateo de Goxendi, Juan Ochoa de Olariaga, Martín de Arteta, el mozo, Martín de Goyru y Juan de Olariaga.

49 ACHÓN INSAUSTI, J.A.: "A voz de concejo..., 154-162. 


\begin{tabular}{|c|c|c|c|c|c|c|c|}
\hline Ochoa Báñez I & $\begin{array}{l}1422 \\
1435 \\
1436 \\
1450\end{array}$ & $\begin{array}{l}1420 \\
1429 \\
1431\end{array}$ & & & & & \\
\hline Juan Báñez I & & 1403 & & & & 1406 & \\
\hline Juan Báñez II & & 1460 & & & & $\begin{array}{l}1454 \\
1458 \\
1460 \\
\end{array}$ & \\
\hline Martín Báñez II & 1489 & & & & & & 1488 \\
\hline Asencio Báñez I & 1483 & & & & & & \\
\hline Asencio Báñez II & & & $\begin{array}{l}1509 \\
1517 \\
\end{array}$ & $\begin{array}{l}1513 \\
1515 \\
\end{array}$ & 1515 & & $\begin{array}{l}1501 \\
1511 \\
\end{array}$ \\
\hline Juan Báñez & & & & & & & 1519 \\
\hline Martín Báñez & $\begin{array}{l}1505 \\
1510 \\
\end{array}$ & & & & & & \\
\hline
\end{tabular}

Fuente: elaboración propia a partir de los datos aportados por ACHÓN INSAUSTI, J.A.: “ $A$ voz de concejo..., 122 y HerRero, v.J.: Fuentes medievales..., 101-209.

\section{LINAJES URBANOS Y PARIENTES MAYORES}

En casos como el de Mondragón, el control de los bandos sobre la vida concejil, al menos hasta 1454, fue prácticamente total. Los bandos se repartían los oficios concejiles, los cabezas de bando custodiaban las llaves de la villa y numerosas reuniones del concejo se celebraron en casas particulares de miembros de los bandos, además de en la parroquia. Todo ello se tradujo en una clara mediatización del gobierno concejil. Como demuestra Achón Insausti de 370 menciones de cargos concejiles, se constata que la mayor parte pertenece a los bandos, con miembros de familias como los Artazubiaga, Olabarrieta, Orozco, Echavarría, Oleaga y Ciorrola, entre los gamboínos, y los Arrazola, Otalora, Salinas, Vidaur, Avendaño, Cuadra y Oro, entre los oñacinos. Familias que, a pesar de la abolición de los bandos en 1490, siguieron monopolizando la vida política, administrativa, social y económica de Mondragón hasta más allá de 1520. Como en el caso de los Báñez de Artazubiaga, lo que caracteriza a todos estos linajes es lo que el citado autor denomina "estrategia adaptable y multidireccional", que incluso puede parecer contradictoria a los ojos de los actuales historiadores y que lleva a replantear nuevamente la idea del triunfo de las élites urbanas sobre los Parientes Mayores y la derrota de éstos ${ }^{50}$.

En realidad, los Parientes Mayores y los hidalgos rurales tenían presencia en las villas guipuzcoanas desde el siglo XIV, como corroboran los casos hasta ahora

50 LEMA PUEYO, J.A.: "“Por los procuradores de los escuderos hijosdalgo": de la Hermandad General a la formación de las Juntas de la Provincia de Guipúzcoa (siglos XIV-XVI)", El triunfo de las elites urbanas guipuzcoanas: nuevos textos para el estudio del gobierno de las villas y de la Provincia (14121539), Diputación Foral de Gipuzkoa, San Sebastián, 2002, 59-113 y FERnÁndez DE PINEDO, E.: "Prólogo", El triunfo de las elites urbanas..., 15-19. En una anterior ocasión ya planteamos nuestras reservas en torno a estas teorías. Véase ARAGÓN RUANO, A.: "La importancia de los montes comunales en el desarrollo de la sociedad urbana vasca en el tránsito del medievo a la modernidad (siglos XV y XVI)", Boletín de la Real Sociedad Bascongada de Amigos del País, San Sebastián, Tomo LIX, 1 (2003), 59-104. 
descritos de Azpeitia, Mondragón, Villafranca de Ordicia y Zumaya. Fueron sobre todo los hijos segundones de dichos linajes quienes se vieron abocados a buscar nuevos horizontes, ante la progresiva generalización del sistema de heredero único. En algunos casos, también los propios cabezas de linaje y mayorazgos acabaron por trasladarse a las villas, toda vez que su presencia en el medio urbano era esencial si querían participar de su expansión económica y jurisdiccional. A través de diferentes estrategías consiguieron finalmente llegar a la cúspide del poder local, iniciando y protagonizando el ya descrito proceso de oligarquización ${ }^{51}$.

El propio Achón Insausti ${ }^{52}$ asegura que “...esa reunión política "cerrada” que representa a la universitas sigue siendo una reunión de banderizos, aunque ya por poco tiempo", y habla del triunfo de la vinculación política corporativa sobre la personalizada. Sorprendentemente, el mismo autor matiza páginas más tarde que “...la eliminación de los bandos y la plasmación de una estructura política corporativa en Gipuzkoa no debe interpretarse en términos de pérdida absoluta de peso específico e influencia de los antiguos banderizos. En cualquier caso conviene matizar y relativizar la "derrota" banderiza, limitándola a su más estricto significado: la imposibilidad de que antiguos oñacinos y gamboínos pudiesen acceder, como tales banderizos, a los cargos políticos propios de la estructura corporativa (concejos, Juntas Generales, etc.)". Sin embargo, esta afirmación no es del todo correcta, pues todavía en 1520 muchos de nuestros protagonistas seguían ocupando importantes cargos concejiles; el propio Juan Báñez de Artazubiaga aparece en 1519 como diputado. A pesar de que el mencionado autor considera el de Mondragón un caso excepcional en el contexto guipuzcoano, la documentación demuestra que la pervivencia de los Parientes Mayores y su influencia en la vida concejil guipuzcoana fue un hecho más que habitual en el resto de villas.

Una prueba fehaciente de ello es la Real Cédula de 28 de marzo de 1481 por la que los Reyes Católicos confirmaron una ordenanza provincial que prohibía a los Parientes Mayores, sus hijos, sus mujeres o a cualquier otra persona poner por sí o por medio de intermediarios, alcalde u otro oficial concejil cualquiera, aplicando el castigo tanto a quienes obrasen de esa guisa como a quienes aceptasen los cargos $^{53}$. A pesar de todo, con posterioridad se siguió transgrediendo. Allá por 1488 se afirmaba que los Báñez de Artazubiaga ponían y elegían "de su mano" los cargos concejiles, eligiéndose a sí mismos o a sus acólitos, transgrediendo las ordenanzas

51 ARAgón RUANO, A.: "La pervivencia de los Parientes Mayores..., 283-312; DíAZ DE DURANA, J.R.: "Linajes y bandos en el País Vasco..., 279.

52 ACHÓn insausti, J.A.: “ $A$ voz de concejo..., 191-199.

53 “...e porque no pueden ser libres ni igoales los que de mano de poderosos non iguales e apasionados de la dicha provincia toman las dichas alcaldias e otros oficios concejiles e son puestos en ellos e por evitar toda subjecion e yugo...según vemos cada dia...que ningunos parientes mayores ni otra persona alguna no se entremeta a poner de su mano alcalde ni otros oficiales publicos de ningun concejo de esta dicha provincia so pena de 100 doblas...que los dichos parientes mayores, ni sus hijos ni sus mujeres ni ninguno ni alguno de ellos ni otra persona alguna por si ni por interpositas persona o personas no procuren ni sean osados de sacar como los dichos oficiales...por su mano...". Archivo General de Gipuzkoa (AGG-GAO), JD IM 1/11/28. 
provinciales, denuncia que también se hacía desde Motrico $^{54}$. El propio año $1490^{55}$, tras la abolición de los bandos, se denunciaba que no era cumplida, existiendo "... confederaciones y vandos e parcialidades asy en la elección de los alcaldes ordinarios e otros ofiçios...". El problema era nuevamente denunciado en 1500 y en 1513, año en el que se advertía de la existencia de "parcialidades" que ejercían su influencia a través de los electores ${ }^{56}$. De hecho, las ordenanzas de Oyarzun de 1501, surgieron precisamente como respuesta a ese contexto, puesto que como afirma el capítulo segundo de las mismas, con anterioridad algunas personas solían nombrar alcaldes, antes incluso de ser elegidos por el concejo, con la intención de "revolver", lo que dio lugar a numerosos pleitos ${ }^{57}$.

En 1516, los más importantes linajes banderizos (Zarauz, Achega, Murguía, Leizaur, Lazcano, Yarza, Arriarán, Gaviria, Unzueta, Olaso, Balda, Loyola e Iraeta) seguían enfrentándose a los decretos provinciales, negándose a aceptar la intermediación de los concejos y la provincia en su relación con el rey y reuniéndose a pesar de no tener facultad para celebrar juntas. El 3 de noviembre de 1516 una Real Orden ordenaba al corregidor de Guipúzcoa que hiciese información sobre las Juntas que realizaban los Parientes Mayores. Antonio de Achega, en nombre de los Parientes Mayores, encabezados por Bernaldino de Lazcano ${ }^{58}$ y Martín Ruíz de Gamboa, alegaba que eran ellos eran los fundadores de la provincia y tenían derecho a reunirse; ante las acusaciones de constituirse en "monipodio" 59 , preferían considerarse "Santa Congregación". La provincia, sin embargo, alegaba que las villas y lugares eran anteriores a los Parientes Mayores y que el rey, cuando había necesitado de servicios militares, había acudido a la provincia no a los Parientes Mayores ${ }^{60}$. Sin embargo, eso no parece del todo cierto si hacemos caso del ejemplo de Juan de Gaviria, quien el 22 de junio de 1572 recibió una Real Cédula para que aprestase un destacamento militar, juntando a sus deudos, parientes y allegados, en

${ }^{54}$ AGS, RGS, XI-1488, fol. 63 y Cédulas Reales, leg, 72, nº 2, fol. $1 \mathrm{v}^{\mathrm{o}}-2 \mathrm{r}^{\mathrm{o}}$.

55 El mismo fenómeno se produjo en Azcoitia años antes, en 1484, cuando se redactaron nuevas ordenanzas, confirmadas por los Reyes Católicos, a fin de acabar con la inseguridad social provocada por la lucha de bandos, y coetáneamente en Vergara, donde el 20 de julio de 1490 los Reyes Católicos redactaron una Real Provisión prohibiendo los bandos y parcialidades de Ozaeta y Gaviria, estableciendo que todos los vecinos de Vergara tuviesen la misma consideración, es decir, "juntamente llameis de Vergara" y se eligiese un único alcalde ordinario, dos fieles, un procurador del concejo, un jurado y un preboste, el día de San Miguel de cada año. AYerbe IRIBAR, M.R.: Documentación medieval del Archivo Municipal de Azkoitia (m.s. XIII-1500), Eusko Ikaskuntza, San Sebastián, 1993, 155-161 y AGS, CCA, MYE, Leg. 161-261.

56 AGS, RGS, VII-1490, fol. 46 y Archivo Municipal de Mondragón (AMM), Leg. 9, fol. 12 vº.

57 AMO, C, 1, 1, 6.

58 Este personaje fue protagonista, entre los años 1497 y 1499, de un curioso episodio en el que se le acusó de haber renegado y blasfemado contra Dios, la Veracruz y los santos, no sabemos si fundada o infundadamente y como parte de la estrategia de asedio contra los Parientes Mayores, siendo declarado en rebeldía y contumaz, y condenado a perder la lengua, la mitad de sus bienes y al pago de $12.000 \mathrm{mrs}$ y $1.488 \mathrm{mrs}$ de costas. AGS, CCA, Pueblos, Leg. 9, 1, 116 (2).

59 Se debe recordar que el título XXVIII de los Fueros de Guipúzcoa, que recogía legislación entre 1460 y 1482, prohibía expresamente la formación de "ligas, monipodios, confradias y vandos". Nueva Recopilación de los Fueros, privilegios, buenos usos y costumbres, leyes y órdenes de la muy noble y muy leal Provincia de Guipúzcoa, 1696, La Gran Enciclopedia Vasca, Bilbao, 1980, 288-289.

${ }^{60}$ AGG-GAO, JD IM 1/6/18. 
número de 200, a fin de acudir con ellos a Flandes o la armada que iba a Francia. El destacamento, una vez aprestado, estuvo a la espera cerca de tres mees, siendo proveido de armas, arcabuces y librea de paño verde, lo cual le generó a Gaviria un alto desembolso y costo que le obligó a empeñar su hacienda, por lo que en 1579 elevó un pedimiento ${ }^{61}$.

El problema de las Juntas de Parientes Mayores se prolongó incluso hasta el siglo XVII, cuando se produjeron nuevos conatos. Todavía en una fecha como 1624, los Berástegui, Eraso, San Millán, Zabala y Lizaur se reunieron en Villabona, sobre el modo de servir al rey con gente armada, siendo ellos los caudillos. Juan Pérez de Lizaur, en representación del resto, demandaba que en los levantamientos de gentes no fuesen obligados a alistarse bajo la bandera de las villas en cuyas jurisdicciones habitaban, como pretendía la provincia, y fuesen elegidos como capitanes y coroneles, obligándose cada uno a acudir con...j100 soldados!, lo cual habla de su preeminencia social y redes clientelares.

Aunque el procedimiento se inició el 9 de marzo de 1624, no fue hasta el 20 de abril de 1624 cuando las Juntas Generales de Elgóibar ordenaron a los Parientes Mayores presentarse ante ellas y que, siendo remisos, se les hiciese presos y se secuestrasen sus bienes. Francisco de Berástegui huyó a Baraibar y Azcárate, en Navarra, mientras que Martín de Zavala Idíaquez, vecino de Usúrbil, Miguel de San Millán, vecino de Cizúrquil, y Luis de Lizaur, vecino de Andoain, fueron interrogados. En sus alegaciones explicaban que habiendo sido convocados por la provincia para armarse, se juntaron en Villabona para ver cómo podían servir a su majestad, pues no se les dejaba ostentar oficios públicos como al resto de hidalgos. Todo lo tratado en la reunión fue verbal y nada fue redactado, ni enviado a la Corte; ni siquiera se habló de coronelías o capitanías, sino únicamente de cómo las 23 familias de Parientes Mayores existentes en la época podían servir mejor al rey. Además, durante el proceso y en su descargo, los Parientes Mayores mandaron imprimir un Discurso defensorio, en el que llama poderosamente la atención la concepción que, en pleno siglo XVII, tenían de su propio papel y del lugar que debían ocupar en la estructura política ${ }^{62}$. Zavala, San Millán y Lizaur fueron absueltos, siendo obligados ellos y sus sucesores a no volver a realizar junta alguna. En el caso de Francisco de Berástegui y de Miguel de Areso, la Junta Particular de Azpeitia de 12 de octubre de 1624 abrió autos contra ellos y quiso aplicar una sentencia ejemplar, pues decretó el secuestro de sus bienes, su condena a cuatro años de destierro, dos

${ }^{61}$ AGG-GAO, CO ECI 361.

${ }^{62}$ AGS, CCA, Pueblos, Leg. 9, 117, fols. $2 \mathrm{r}^{\mathrm{o}} \mathrm{y} \mathrm{v}$. “...Y aunque habitan los Parientes mayores en Guipuzcoa, y sus casas estan en ella, y por esta parte se quiera dezir que son vecinos, y que basta que lo sean para que ayan de estar a sus ordenes, se alegara en contrario, que son vasallos de $\mathrm{Su}$ Magestad solamente, y que no estan vnidos y hermanados con Guipuzcoa, sino que quedaron fuera de su hermandad, quando ella tuvo principio, que ha menos de 300 años, y siempre separados, asi se han conservado sin auer contribuido en los gastos de la Republica, como lo hazen todos los demas della sin excecion de nadie...la desunion y singularidad suya los haze libres de obedecer al gobierno comun de la Prouincia...". El subrayado es nuestro. Fernández albaladeJo, P.: La crisis del Antiguo Régimen en Guipúzcoa, 1766-1833: cambio económico e historia, Akal, Madrid, 1975, 159-160 y DíAz DE DURANA ORTIZ DE URBINA, J.R., FERNÁNDEZ DE LARREA, J.A.: "El discurso político de los protagonistas de las luchas sociales en el País Vasco al final de la Edad Media", Annexes des CLCHM, Lyon, 16 (2004), 315. 
obligatorios y dos voluntarios, y el pago de 1.000 ducados cada uno, más las costas del proceso. Sin embargo, el rey no admitió el decreto y los amnistió ${ }^{63}$.

Volviendo al hilo argumental iniciado, el 8 de diciembre de 1518 Pedro de Nava, corregidor de Guipúzcoa, y el regimiento de Azpeitia, con confirmación real, se vieron obligados a redactar una ordenanza sobre los Parientes Mayores. Para garantizar la "paz e sosiego" de la Hermandad de Guipúzcoa y de la villa, ante los "...insultos, inconvenientes e muertes de ombres" y los "...alborotos e parcialidades..." surgidos a consecuencia de ello, que en fechas recientes se habían producido, se ordenaba a los alcaldes, fieles y regidores del concejo de Azpeitia que anualmente hiciesen sus ayuntamientos y regimientos con todos aquellos a quienes quisiesen llamar, excepción hecha de los Parientes Mayores, que no podrían acudir, ni residir ni tener voz ni voto, so pena de la mitad de los bienes de los mencionados oficiales concejiles que incumpliesen dicha ordenanza y de los Parientes Mayores. En caso de tener que acudir a alguna reunión concejil para tratar algún negocio propio, los mencionados Parientes Mayores deberían avisar primero a los oficiales, y, una vez hecha la relación y defensa del asunto, deberían abandonarla. En caso de que el concejo tuviese alguna cuestión que dilucidar con los Parientes Mayores, entonces sí podría llamarles y ellos acudir, pero sin voz ni voto, estando obligados a salir del lugar de reunión para permitir la discusión y decisión de los miembros del concejo. Esta ordenanza debería permanecer en el libro del concejo, para que nadie alegase desconocimiento.

Parece que los Loyola y sus acólitos protestaron o al menos debieron mostrar su disconformidad, puesto que el 19 de agosto de 1519 el concejo se reunió para enmendar la ordenanza establecida por el corregidor y discutir si los principales aludidos, los miembros del solar y linaje Loyola, que cumplían con sus obligaciones fiscales tanto concejiles como provinciales, como moradores, podían ser excluidos de los concejos generales que por villa o tierra se hiciesen ${ }^{64}$. El concejo decidió que cuando se hiciese ayuntamiento general de todos los vecinos y moradores de Azpeitia, Martín García de Licona, señor de Loyola y sus sucesores pudiesen acudir a dichas reuniones como un morador más, siempre y cuando ni el mencionado Martín García ni sus sucesores tuviesen voz ni voto más que cualquier otro vecino, conforme a la sentencia pronunciada por la Real Chancillería en el juicio entre la villa y la tierra. El resto de la mencionada ordenanza de 1518 quedaba intacto. Seguramente los Loyola no cejaron en su empeño y la aplicación de esta nueva versión provocó nuevos conflictos, puesto que curiosamente el mencionado decreto aparece tachado en el libro del concejo. Más que probablemente fue el regimiento el que tomó esa decisión, puesto que el 9 de septiembre de 1519 volvió a reunirse en las casas del Bachiller Pedro Pérez de Zavala y a discutir sobre la mencionada ordenanza establecida por el corregidor Pedro de Nava. En realidad, nuevamente se rectificó el

${ }^{63}$ AGG-GAO, JD IM 1/6/19.

${ }^{64}$ En el año 1516 el concejo de Azpeitia quiso que las caserías del señor de Loyola pasaran de pechar medio pecho a contribuir como pecheros enteros, lo que provocó pleito entre ambas partes. Para evitar los elevados costos, ambas partes se avinieron a una sentencia arbitral. El concejo eligió seis personas de la tierra y seis personas de la villa para que decidiesen si tal medida era justa o no. Los nombrados, tras largas deliberaciones, acordaron que el padrón debía quedar en el estado en que estaba antes de la subida. AMAzp, 774-01, fols. $26 \mathrm{r}^{\circ}-27 \mathrm{v}^{\mathrm{o}}$ 
anterior decreto de 19 de agosto, ordenando que dicha ordenanza “....se entendiese para los señores de Loyola que de presente son y adelante seran no puedan yr a los concejos que sus antepasados nyn solian yr porque a los concejos e ayuntamientos generales que sus antecesores o antepasados que han seydo señores de la dicha casa e solar de Loyola puedan yr segund e como sus antepasados fueron...", para de esa forma evitar inconvenientes ${ }^{65}$.

La existencia de textos como los descritos demuestra claramente el poder y la influencia que seguían teniendo los Parientes Mayores en el poder concejil en una fecha tan tardía como 1518, más de medio siglo después de que Enrique IV los desterrase o treinta años después de que en Mondragón se aboliesen los bandos. Coincidiendo con el conflicto de las comunidades de Castilla, Azpeitia, Azcoitia, Vergara, Elgóibar y Mondragón, las cinco villas en las que más palpable era la influencia de los Parientes Mayores, además de Guetaria y la Alcaldía Mayor de Areria, propusieron el cambio de sistema de votación en las Juntas Generales de Guipúzcoa, pasando de fogueral a individual. Todavía en 1529 la provincia insistía en que "...los procuradores de juntas generales y particulares no tomen cargo de procurar e juntar en público nin en secreto por algun pariente mayor, e su muger e fijos e familiares, salvo que administren justicia en igualdad, segund que deben de derecho...". Más aún, en 1533, con motivo de la llegada de Carlos I a la provincia, los representantes provinciales fueron presentados al rey por el señor de Lazcano; al cual, al menos hasta 1550, acudían las Juntas Generales para que mediase entre las partes e impusiese paz, en delitos de sangre y enfrentamientos armados ${ }^{66} . ¿$ iFue, por tanto, realmente un triunfo de las élites urbanas o un desplazamiento, desaparición y derrota de los Parientes Mayores de la vida concejil? Rotundamente no; puede que no apareciesen personalmente de una forma directa, pero la red de personas y familias con las que mantenían un vínculo familiar o de amistad e intereses les permitió seguir estando en la "sombra" ${ }^{67}$.

En su caso, los Oñaz y Loyola siguieron contando con los contactos precisos en la corte y en la villa de Azpeitia para ganar algún puesto concejil o contar con algún escribano adepto a su causa, con lo que conseguían un respaldo social interesado e interesante para sus fines, inmersos como estaban en infinidad de procesos, en los que la pericia y conocimientos en leyes de los mencionados escribanos fueron esenciales. Ya en el año 1471 Enrique IV autorizaba a las instituciones provinciales a conocer sobre las "falsías" o falsificaciones que los Parientes Mayores, sus mu-

${ }_{65}$ AMAzp, 774-01, fols. $319 \mathrm{r}^{\mathrm{o}}-321 \mathrm{r}^{\mathrm{o}}$. Es curioso que Marín Paredes no dé prácticamente importancia a estos textos, a pesar de mencionar la ordenanza de 8 de diciembre de 1518 y la de 9 de septiembre de 1519. Sin embargo, nada dice respecto de la de 19 de agosto de 1519. MARÍn PAREDES, J.A.: "Semejante Pariente Mayor..., 236-238, 249-250. El subrayado es nuestro.

${ }_{66}$ Ibidem, 200 y 237; y alberdi lonbide, X., ARAGÓn RUANO, A.: "La pervivencia de los Parientes Mayores..., 287-312.

${ }^{67}$ En el mencionado Discurso Defensorio los propios Parientes Mayores se sonrojaban ante el intento de las instituciones de ensuciar su reputación, debido a las correrías y "rapiñas" de sus antepasados, puesto que "...conociendo en ellos esta y otras grandes calidades, se han emparentado siempre los mas adelantados de Guipúzcoa en reputacion y hazienda con los Parientes mayores Della, y no seria buena consonancia de lo dicho, si se procurasse al presente que fuesen sin honor los con cuya sangre quisieron autorizar, y honrar mas a la suya, aunque tambien noble.”. AGS, CCA, Pueblos, Leg. 9, 117, fol. 6 v . 
jeres, hijos y otras personas cometían; se prohibía a todos ellos, so pena de 1.000 mrs, redactar falsas escrituras y presentar falsos testigos -a quienes corrompían con dinero y dádivas- en las causas judiciales ${ }^{68}$. Además, Beltrán de Oñaz y Loyola procuró emparejar a las mujeres del linaje con familias que contasen con importantes recursos económicos, caso de los Martínez de Lasao o los Egurza, engrandecidos en el servicio a la administración real, los Aquerza o los Martínez de Mallea, dedicados al comercio. Precisamente, quien más nos interesan en esta ocasión son los Egurza. Domingo de Egurza obtuvo a fines del siglo XV una de las escribanías de la villa de Azpeitia, manteniendo el cargo al menos hasta 1516, compaginándolo con el de procurador de Mondragón en Juntas Generales en 1516 y en la Real Chancillería de Valladolid en 1517. En dicho cargo continuaron sus descendientes: Juan Martínez de Egurza, escribano real y del número en 1517, participó como procurador en Juntas en 1515 y 1516 , y fue escribano fiel en 1516, al igual que Juan Pérez de Egurza en 1519, también escribano real y del número, y fiel bolsero en 1520. Según Marín Paredes, es probable que esta situación fuera posible gracias a la mediación de los Oñaz y Loyola, puesto que durante la vida de Martín García de Oñaz y Loyola, padre del mencionado Beltrán, fue un Egurza el escribano que escrituraba sus asuntos, a cambio de lo cual fue recompensado Juan Martínez de Egurza, concretamente con la donación de una huesa de la iglesia de San Sebastián de Soreasu para la sepultura de su familia. La relación entre ambas familias quedó finalmente plasmada en la unión matrimonial entre Juan Pérez de Egurza y Marina Sáez de Loyola ${ }^{69}$. Por lo tanto, los Loyola supieron rodearse de otras familias y linajes que, por su mayor adecuación a las nuevas estructuras políticas concejiles, provinciales y reales, les permitieron, aunque de manera indirecta, seguir participando en el devenir político de las sociedades en las que se asentaban.

\section{CONCLUSIONES}

En la mayoría de los casos, se ha considerado el conflicto banderizo como un síntoma y una prueba más de la crisis bajomedieval -por otro lado, actualmente de difícil constatación en el caso guipuzcoano ${ }^{70} \mathrm{y}$ con importantes matices en los ámbitos peninsular y europeo ${ }^{71}$-, sin tener en cuenta, en la mayoría de los casos, que el momento álgido del enfrentamiento se produjo precisamente durante el siglo XV, período en el que según la misma historiografía ya se habían superado las dificultades y la crisis. Creemos sinceramente que la lucha entre el modelo banderizo y el urbano no se debe a la existencia de una crisis -y el intento de los banderizos de equilibrar o recuperar su nivel de ingresos-, sino, más bien, a la estrategia iniciada

68 AGG-GAO, JD IM 3/8/13.

${ }^{69}$ ACHÓN INSAUSTI, J.A.: “A voz de concejo..., 261-262.

70 ARAGÓN RUANO, A.: "La importancia de los montes comunales..., 65-69.

71 Para una visión general consúltese FuRIó DIEGO, A.: "La crisis de la Baja edad Media: una Revisión", en Las crisis a lo largo de la Historia, Universidad de Valladolid, Valladolid, 2010, 15-44; EIPSTEIN, S.R.: Libertad y crecimiento. El desarrollo de los estados y de los mercados en la Europa de 1300-1750, Valencia, 2009. 
por cada una de las partes implicadas -en este caso sería imprescindible que los historiadores huyéramos de las generalizaciones e individualizáramos y aisláramos cada uno de los linajes, sin englobarlo en equívocas etiquetas, tales como "linajes urbanos", "linajes rurales", etc. ${ }^{72}$ - para capitalizar y monopolizar los beneficios que comienzan a reportar los recursos naturales y las actividades industriales y comerciales de las provincias costeras. Los Parientes Mayores, en desventaja, por las concesiones y la presión real a favor de las villas, tratarán de hacer valer sus privilegios para poder controlar dichos recursos y sus beneficios -en un contexto de clara indefinición territorial y jurídica, hasta que se comiencen a realizar los primeros apeos y amojonamientos y se redacten las ordenanzas municipales ${ }^{73}$ - . Hay que recordar que a pesar de controlar y monopolizar las factorías siderúrgicas, los Parientes Mayores y la nobleza rural no contaban con el control de los recursos necesarios para su fabricación y actividad (vena, leña y madera, canteras, aguas y ríos), ni controlaban la última fase de la comercialización de los productos férricos, ambos en manos de los grupos urbanos, aunque para ello algunos linajes, como los Salazar ya se hubiesen asentado en villas como la de Portugalete.

Sin duda, el gran error que sigue cometiendo la historiografía vasca es considerar a ambos modelos excluyentes, contrapuestos, beligerantes, corporativistas y rígidos, sin tener en cuenta los intereses particulares de cada uno de sus miembros, cuando hay casos que comparten ambos modelos. El hecho de que existiesen enfrentamientos armados y judiciales entre los propios notables rurales, entre éstos y las villas, y entre las propias villas -quienes ya actúan como verdaderos señores jurisdiccionales- no significa que hubiese una crisis económica. Precisamente, el enfrentamiento se produjo porque ninguno de los implicados estaba dispuesto a compartir las nuevas fuentes de riqueza que se fueron desarrollando durante la Baja Edad Media en Guipúzcoa. La pugna en torno al disfrute, uso y acceso a dichos recursos, a pesar de estar siempre ahí, cobró un inusitado interés estratégico y económico, al calor del desarrollo económico europeo y la expansión castellana. También en el ámbito económico se considera que el mundo rural y el mundo urbano eran dos mundos contrapuestos, pero nada más lejos de la realidad, puesto que ya para entonces ambos mundos estaban perfectamente engarzados y estructurados, de tal forma que uno y otro eran necesariamente complementarios e imprescindibles en un territorio que, aunque completamente volcado al mar, necesitaba del abastecimiento rural -en un marco geográfico que incluso supera el ámbito de las provincias vascas y se extiende hacia Navarra, La Rioja y Castilla-, para el desarrollo de esas actividades industriales y comerciales. Como afirma Guy Bois ${ }^{74}$, el responsable de

72 En este sentido, Borja Aguinagalde advierte, acertadamente, que sería conveniente "...hablar de grupos de presión o de grupos de conflicto cuyos integrantes son de una procedencia mucho más diversificada de lo que se cree, y en el que quizás es también posible que, dependiendo del conflicto concreto, cambien también las alianzas". AGUINAGALDE, B.: "La genealogía de los solates..., 158.

73 ARAGÓN RUANO, A.: "Las comunidades de montes en Guipúzcoa en el tránsito del Medievo a la Edad Moderna", Revista de historia moderna: Anales de la Universidad de Alicante, Alicante, 26 (2008), 249-274.

74 BoIs, G.: "Un assaig sobre el naixement y el desenvolupament de l'economia de mercat al si de la societat feudal", Els espais del mercat. II colloqui international d'història local, Diputación de Valencia, Valencia, 1992, 86. 
la economía de mercado -representada por las villas- no es el capitalismo sino la propia configuración feudal.

En definitiva, el conflicto entre el modelo banderizo y el urbano no es más que la lucha por establecer un nuevo modelo de control y monopolización de los recursos, en un momento de expansión de una serie de actividades de alto valor acumulativo y económico, cuya gestión precisa de nuevas fórmulas, primero a través de las villas y después a través de la "provincia" de Guipúzcoa, todo ello bajo el arbitraje de la corona, que es la auténtica interesada en que esas riquezas reviertan en sus arcas. Esto es, el nuevo modelo económico que se está desarrollando en Europa y en el País Vasco atlántico, en el que se fomenta el predominio de las actividades comerciales y de intercambio, frente a la anterior economía agrícola y ganadera de autoabastecimiento, necesita superar los encorsetados marcos jurídicos y financieros del modelo banderizo-señorial. De la mano de la iniciativa regia, que ve en ello nuevas posibilidades para la expansión de su poder, se crea paulatinamente un nuevo marco jurídico que va a permitir la expansión de las mencionadas actividades productivas. De este proceso también quieren participar los Parientes Mayores que, sin embargo, no cuentan con una base jurídica suficiente que se lo permita, por lo que se verán abocados a realizar usurpaciones. Las villas no lo permitirán e iniciarán un largo proceso de recuperación que, en realidad, supuso una segunda señorialización. El modelo urbano debía hacerse con el control económico y jurídico de las materias primas y de los medios de producción, para que todos los beneficios del nuevo modelo recayeran en sus manos -y, a través de él, en las de la corona-. Para ello, a costa de los intereses y derechos de las comunidades a quienes supuestamente representaban, crearon auténticos monopolios sobre montes, bosques, ríos, molinos, abastecimiento, etc., iniciando así un proceso de recorte de usos, hasta entonces gratuitos, libres y colectivos ${ }^{75}$.

A partir de este momento, todo aquél que quiera participar de esos monopolios y aprovechamientos, lo deberá hacer dentro del nuevo marco jurídico marcado y representado por las villas -uno de sus principales instrumentos serán las ordenanzas municipales-. Precisamente para lograrlo, algunos miembros de los linajes rurales iniciaron hacia el siglo XIV su traslado físico hacia las villas. Como afirma Borja Aguinagalde, desde sus orígenes, hacia finales del siglo XIV, los linajes de Parientes Mayores estaban ya involucrados en las villas y con las familias que las gobernaban. Para ello se sirvieron de una política matrimonial que les relacionara con los principales linajes urbanos o les permitiera asentarse en las villas, cuyos resortes administrativos tratarán de controlar, directa o indirectamente -por medio de sus bastardos y segundones-, mediante su prestigio y poder, todo ello a fin de beneficiarse de los recursos monopolizados por los concejos; para finales del siglo $\mathrm{XV}$ la simbiosis entre linajes de la tierra y linajes urbanos es un hecho en la mayoría de los $\operatorname{casos}^{76}$. Este proceso es muy claro, por ejemplo, en las villas de litoral

75 ARAGÓN RUANO, A.: "La importancia de los montes comunales..., 65-69 y "La evolución de la economía guipuzcoana en tiempos de Urdaneta: un período de desarrollo y expansión entre supuestas crisis", Andrés Urdaneta: un hombre moderno, Ayuntamiento de Ordicia, Ordicia, 2009, 119-144.

76 AGUinAgalde, B.: "La genealogía de los solares..., 157-158 y "Notas sobre los niveles estamentales más elevados de la estratificación social en Guipúzcoa en 1450-1550: La zona del Bajo Urola”, Boletín 
guipuzcoano, con linajes de primer orden como los Ortiz de Zarauz en Zarauz o los López de Zarauz en Guetaria, que volvieron a copar las instituciones provinciales en la segunda mitad del siglo XVII, aunque, en realidad, jamás habían desaparecido de ellas y de las municipales ${ }^{77}$. Unos y otros, por medio de las mencionadas fusiones y vínculos familiares, iniciaron un proceso de expansión a otras villas -por ejemplo, tan distantes como Motrico y Fuenterrabía- donde también accedieron a los cargos de gobierno. El modo de distribución no se correspondió con la distribución banderiza, sino que más bien respondió a los intereses económicos de cada linaje, estableciéndose tanto en territorio oñacino como gamboíno. Los linajes más dinámicos y con mayor expansión -lo cual sí responde a una lógica esencialmente económica- fueron los de las principales villas guipuzcoanas de la época: Azcoitia, Azpeitia, Deva, Mondragón, Motrico, San Sebastián y Tolosa ${ }^{78}$.

Como ya se ha defendido en otra ocasión, los Parientes Mayores no estaban preparados para los nuevos tiempos. La mayor parte de los miembros que detenta puestos de gobierno en las villas y la provincia -con alguna rara excepción- eran gentes con un alto nivel de formación y alfabetización. La mayoría eran escribanos y algunos poseían titulación superior en leyes, ya que recibían el tratamiento de "Bachilleres" y de "Licenciados". No es casualidad que de unos 340 individuos que ocuparon los cargos concejiles villanos en Azpeitia, Mondragón, Motrico, Villafranca de Ordicia y Zumaya entre 1450 y 1520 , cerca de 50 fuesen escribanos reales y del número, es decir, casi un $15 \%$. El número de alfabetizados subiría en caso de incluir letrados, bachilleres y mercaderes. Bajo esta perspectiva, los Parientes Mayores tenían pocas oportunidades, pues su función social hasta el momento había sido la militar y lo seguiría siendo hasta el siglo XVII. Por tanto, la inadecuación al nuevo Estado Moderno burocrático, y lo extemporáneo del modelo guerrero y militar del Estado Feudal, al que estaban acostumbrados los Parientes Mayores -aunque no en todos los casos-, fue lo que les apartó, durante un corto período de tiempo, del liderazgo directo y personal de la provincia ${ }^{79}$. Como ya hemos visto -a pesar de que la ordenanza del corregidor del año 1511 no lo incluía-, precisamente uno de los requisitos para la obtención de un cargo concejil era saber leer y escribir en lengua castellana, lo que reducía el número de candidatos. Pero los Parientes Mayores no tardaron en reaccionar y amoldarse a los nuevos tiempos; fueron sus descendientes, en muchos casos líneas bastardas, los que, ante su incapacidad de acceso a la línea de sucesión del tronco del linaje, buscaron alternativas en el ámbito de la burocracia y la administración, recibieron formación intelectual y, con

de estudios Históricos sobre San Sebastián, San Sebastián, 16-17 (1982-1983), 304-340. Véase también GARCÍA DE CORTÁzAR, J.A.: "Álava, Guipúzcoa y Vizcaya en los siglos XIII a XV: de los valles a la provincias", RIEV, San Sebastián, 45, 1 (2000), 228 y 230.

77 ARAGÓN RUANO, A.: " "En una casa y mantenimiento”. Estrategias familiares en Guipúzcoa durante la Edad Moderna a través del caso de la familia Zarauz", Nuevo Mundo Mundos Nuevos. Coloquios, 2008 (Familia y organización social en Europa y América siglos (XV-XX), Murcia-Albacete 12-14 diciembre 2007, edición en línea (http://nuevomundo.revues.org/17153).

78 ALBERDI LONBIDE, $x$, ARAGÓN RUANO, A.: "La pervivencia de los Parientes Mayores..., 307-310.

79 Nuevamente acudimos a las palabras de Borja Aguinagalde, quien afirma que el conflicto se saldó “...con la victoria de una manera de ver las cosas, no con la victoria de unos linajes sobre otros". AGUINAGALDE, B.: "La genealogía de los solares, 159. 
el tiempo, volvieron a ocupar cargos de máxima importancia en las instancias de poder local y provincial. Transcurrido el siglo XVI y los cambios que en él se orquestaron, nuevamente se volvieron a ocupar de forma personal de la oeconomía provincial ya en el siglo XVII, como demuestra el caso de los Ortíz de Zarauz y López de Zarauz ${ }^{80}$. Por tanto, estas familias siguieron presentes en la vida concejil y provincial guipuzcoana, al menos hasta 1550 , aunque también se incorporaron algunas nuevas ${ }^{81}$.

80 Concretamente, Martín Ortiz de Zarauz y Andonaegui, que sucedió en el tronco principal y obtuvo el vínculo de Zarauz y Arizterrezu, fue alcalde de Zarauz y Azcoitia, y Diputado General de Guipúzcoa. Su hijo, José Antonio de Zarauz, Gamboa y Larriña, vistió con dieciocho años el hábito de Santiago, fue Diputado General en 1671 y alcalde de Zarauz en 1677, 1689, 1707 y 1708. ARAGÓn RUANO, A.: "En una casa y mantenimiento...

${ }^{81} \mathrm{Si}$ observamos la relación de linajes a los que pertenecen los procuradores de los concejos en las Juntas Generales entre 1511 y 1550, los nombres se repiten. Así en Zumaya encontramos a los Aguinaga, Arbestain, Arteaga, Echezarreta, Elorriaga, Indaneta, Sasiola y Zumaya; en Villafranca de Ordicia a los Albisu, Arza, Iribe, Isasaga, Mújica y Zavala; en Azpeitia a los Acharan, Altuna, Alzaga, Aquemendi, Arrieta, Arsuaga, Celayarán, Eguibar, Eizaguirre, Irarraga, Garín, Goyaz, Lasao, Loyola, Uranga y Zubizarreta; y en Mondragón a los Abarrategui, Avendaño, Albistur, Arcarazo, Artazubiaga, Garibay, Guesalibar, Ocariz, Ochandiano, Oro, Orduña, Urrupain y Vergara. ALBERDI LONBIDE, X, ARAGÓN RUANO, A.: "La pervivencia de los Parientes Mayores..., 287-312. 